\title{
Surface Air Temperature Variability over the Arabian Peninsula and its Links to Circulation Patterns
}

\author{
Raju Attada ${ }^{1}$, Hari Prasad Dasari ${ }^{1}$, J. S. Chowdary ${ }^{2}$, Ramesh Kumar \\ Yadav $^{2}$, Omar Knio ${ }^{3}$ and Ibrahim Hoteit ${ }^{1, *}$
}

1. King Abdullah University of Science and Technology (KAUST), Physical Sciences and Engineering Division (PSE), Thuwal, 23955-6900, Saudi Arabia

2. Indian Institute of Tropical Meteorology (IITM), Pashan, Pune-411008, India

3. Physical Sciences and Engineering Division (PSE), Computer, Electrical, and Mathematical Science and Engineering, Thuwal, 23955-6900, Saudi Arabia

*Corresponding author: Prof. Ibrahim Hoteit,

King Abdullah University of Science and Technology (KAUST),

Physical Science and Engineering Division (PSE),

Thuwal 23955-6900, Saudi Arabia.

E-mail: ibrahim.hoteit@kaust.edu.sa 


\section{Abstract}

2

This study investigates the long-term variability of surface air temperature (SAT) over the Arabian Peninsula (AP), using data from the Climate Research Unit (TS 3.22) for the 19602010 period. The long-term climatology suggests that the warmest AP mean temperatures occur during summer, with the highest temperatures over the northern AP (NAP), due to the monsoon-desert mechanism. During winter, the NAP exhibits low SATs under the influence of western disturbances originating from the Mediterranean. The southwestern AP exhibits the lowest temperatures because of its proximity to the Arabian Sea cold waters, and also because of the orographic effects. The interannual variability of the SAT is stronger during winters. A linear trend analysis reveals a significant increase in the SAT anomaly $\left(0.10^{\circ} \mathrm{C}\right.$ decade $\left.{ }^{-1}\right)$ across the AP, consistently with the global temperature anomalies. Besides the local convective heating, summer SAT variability is associated with the weakening of the Asian jet stream and a Rossby wave train from the Indian Ocean. This variability is also influenced by the anomalous low pressure over the North Atlantic and the Sahara, a high pressure system over Siberia and the northwest Pacific. Both in spring and autumn, sea surface temperature (SST) variations over the Indo-Western Pacific are highly influenced the AP SATs, whereas winter SATs are modulated by the subtropical jet stream and the Middle East jet stream. In all seasons, the AP SAT is strongly influenced by the SST variations over the tropical oceans. The temperature variability is closely associated with the El Niño-Southern Oscillation (ENSO), North Atlantic Oscillation (NAO), and Arctic Oscillation (AO). The warm phase of ENSO (i.e. El Niño) is one possible reason behind the interannual increase in SAT over the southern AP. The negative phases of NAO and AO also play a role in increasing AP SAT. 


\section{Introduction}

27 The climate of the Arabian Peninsula (AP) is extremely arid, a dry climate zone (BWh) by the Köppen climatic classification (Köppen and Geiger, 1936). The combination of a short rainy winter with a long, hot and dry summer imposes a significant strain on freshwater resources (Abdulrazzak and Khan,1990; Rogers and Lydon, 1994; Dabour 2006; Al-Zahrani 2010; Bannayan et al. 2010; World Bank 2010; Al-Zahrani and Baig 2011; Kaniewski et al., 2012). As a result, the AP is sensitive to climate fluctuations and is also highly vulnerable to climate change impacts (Almazroui et al., 2013). Surface air temperature (SAT) is an integral component of climate variability, and is a key measure of climate change on regional and global scales (e.g. Kothawale et al., 2010). Vinnikov et al. (1990) have suggested that the mean SAT has been a good indicator of the state of the climate, because of its important role in the surfaceatmosphere energy exchange processes over the Earth's surface.

Assessing increases in global and regional temperatures has been a high priority of climate change studies, particularly over last 50 years (Fernández-Montes and Rodrigo, 2011). As per the Fourth Assessment Report (AR4) of the Intergovernmental Panel Climate Change (IPCC), the global mean surface temperatures have risen by $0.74^{\circ} \mathrm{C}$ in recent century (IPCC, 2007), particularly, in last 50 years during which the warming rate has been doubled $\left(0.13^{\circ} \mathrm{C}\right.$ per decade). The latest AR5 report from the IPCC states that it is extremely likely that the anthropogenic (human) influence has been the dominant cause of the observed warming, since the mid-twentieth century (IPCC, 2013). Although climate change is well documented on a global scale, its magnitude varies between regions and at different timescales. Warming and cooling trends also vary by season and by region. Moreover, there is increasing evidence of a significant relationship between rising air temperature and the occurrence of weather extremes (Alexander et al. 2006). 

variability research, compared to regions from other developed countries (e.g., Almazroui, 2016). Therefore, many research groups have recently started investigating the climate variability of SAT over the AP and its surrounding regions (Alkolibi 2002; Hasanean and Basset 2006; Al Sarmi and Washington, 2011; 2014; Almazroui et al., 2012; Athar, 2012; Lelieveld et al. 2012; Tanarhte et al. 2012; Almazroui et al., 2013, 2014; Alghamdi, 2014; Hasanean and Almazroui, 2016). Al Sarmi and Washington (2011) analyzed in situ data over the period 1980-2008, which suggested a significant impact of climate change on temperature in the region. Nasrallah and Balling (1993) reported a significant warming trend in temperature, over the Middle East. Additionally, Almazroui et al. (2012) reported a warming rate of $0.60{ }^{\circ} \mathrm{C}$ per decade, based on the annual mean air temperature across Saudi Arabia. Most of these studies have investigated SAT variations over short time periods, using point observations or coarse resolution reanalysis data (e.g. Hasanean and Al-Khalaf, 2012; Hasanean and Almazroui, 2016). Moreover, the analysis of the AP climate variability during the spring and autumn seasons has received much less attention than during summer and winter seasons. Most studies have focused on summer because of its highest temperatures and associated heat stress, whereas winter temperature is explored because of low temperatures due to rainfall. One of the main goals of this study is to characterize the long-term SAT variability and its trends over the AP region for all seasons, on an interannual timescale, using 5 decades (1960-2010) of SAT data.

Regional SATs are modulated by the various teleconnection patterns of the North 71 Atlantic Oscillation (NAO), the Arctic Oscillation (AO), the El Niño-Southern Oscillation 72 (ENSO) and the associated atmospheric circulation patterns (Hasanean 2004; Hasanean and 73 Basset 2006; Hatzaki et al., 2007; Yadav et al. 2009; Chowdary et al. 2014; Hasanean and 74 Almazroui 2016; Dasari et al. 2017). Numerous studies have explored the relationship between 
the regional climate variability and the large scale circulation patterns (e.g. Hasanean and Basset, 2004; 2006 for Egypt; Ghasemi and Khalili, 2006 for Iran; Segele et al. 2009 and El Kenawy et al. 2016b for the Middle East; Gamiz-Fortis et al. 2011 for Europe). Regionally, Cullen et al. (2002) studied the impacts of the NAO variability on the Middle Eastern climate and stream flow. Almazroui, (2006) investigated the teleconnection between the atmospheric circulation patterns and the surface climatic variables in Saudi Arabia. Athar and Ammar (2016) outlined the role of NAO and AO in modulating the moisture flux over the AP region. Hafez (2016) reported that temperature variability in Saudi Arabia is influenced by ENSO. Hasanean and Almazroui (2016) reported that the tropical Atlantic Ocean influenced the AP temperature, in summer by modulating the Indian monsoon low. Abualnaja et al. (2015) found that the Red Sea climate was strongly influenced by the different climate indices such as NAO, the Eastern Atlantic-West Russia pattern, ENSO, the Indian monsoon and Indian Ocean dipole indices. However, many aspects of the seasonal temperature variability over the AP from longterm reasonable resolution datasets have not, still, be fully explored. Moreover, our knowledge about the links between the AP temperatures and large-scale circulation patterns is still limited (e.g. Donat et al. 2014; Almazroui et al. 2015).

This study presents a full analysis of the AP temperature climatology, trends, variability and their links with large scale circulation patterns, which is essential for understanding the climate variations over the AP, and for building climate monitoring capabilities for the region. In particular, it focuses on investigating the influence of the major climate modes, ENSO, NAO and $\mathrm{AO}$, and their roles in modulating the AP climate variability for the various seasons, on an interannual time scale. It further explores the possible underlying mechanisms of the AP SAT variability and its link to the large-scale circulation patterns.

The paper is organized as follows. Section 2 describes the datasets and methods. Section 3 examines the interannual SAT variability and trends over the AP. Section 4 
investigates the links of SAT to dominant circulation patterns. Section 5 provides a summary

101 of the main findings and conclusions.

102

103

104

105

106

107

108

109

110

111

112

113

114

115

116

\section{Data and Methods}

SAT data were extracted from the CRU (TS 3.22), University of East Anglia, for the period 1960-2010. This climate dataset was generated from 1901 to 2016 based on observations from more than 4000 weather stations, available at a $0.5^{\circ} \times 0.5^{\circ}$ spatial resolution (Harris et al. 2014), to provide the best estimate of the spatial patterns of climate variables over the last century. In our study, we restricted our analysis to the last five decades during which observations were more abundant. Indeed, our analysis showed that results for this period were almost identical to those obtained using the entire dataset. SAT anomalies were calculated based on the climatology of the period 1961-1990, which is the standard normal period recommended by the World Meteorological Organization as was also considered in previous regional studies (e.g. Lelieveld et al. 2012; Almazroui 2013). CRU data were further validated using in situ observations of monthly mean temperatures collected from 24 ground stations covering the AP. These provide data from 1901 onwards from six stations, from 1931 onwards from four stations, and from 1950 onwards from the remaining stations. The results obtained for all 24 stations were found in very close agreement with the CRU data, with a correlation coefficient of more than 0.95 , at $95 \%$ significant level. The significance test was performed using a Student's t-distribution with $(\mathrm{N}-2)$ degrees of freedom, where $\mathrm{N}$ is the number of years in the record. Almazroui et al (2012) conducted a thorough comparative analysis of CRU data and in situ measurements over the AP and also found the results using both sets of data to be in very good agreement. The monthly values of each year were averaged to produce a time series of annual mean temperatures. The AP seasons were defined based on AlSarmi and Washington (2011, 2014); winter from December through February (DJF), spring from March through April (MA; 1st transitional period), early summer from May through June (MJ; pre- 
125 monsoon), summer from July through September (JAS) and autumn from October through

126 November (ON; 2nd transitional period or post-monsoon).

128 data from the National Oceanic and Atmospheric Administration (NOAA) Extended

129 Reconstructed SST (ERSST) (Smith et al., 2008; Huang et al., 2015), available at $2.0^{\circ} \times 2.0^{\circ}$

130 resolution, for the period 1960-2010. Several studies showed that the SST variations had a

131 significant influence on the global-mean SAT variability through global atmospheric

132 circulations and the associated energy transportation (Yadav et al., 2009; Almazroui et al.,

133 2014; Chowdary et al., 2014; Roxy et al., 2014). Tropical ocean SST is also known to influence

134 the regional climate variability (e.g. Lanzante, 1996; Hasanean and Almazroui, 2016).

135 Recently, Merrifield and Xie (2016) demonstrated that the mid-latitude SAT variability was

136 influenced by the equatorial Pacific, the tropical Atlantic and the Indian Ocean SSTs. The

137 twentieth-century atmospheric reanalysis (Poli et al. 2016) of geopotential height, zonal and

138 meridional wind components and mean sea level pressure (MSLP), available at $1.125^{\circ} \times 1.125^{\circ}$

139 (approximately $125 \mathrm{~km}$ ) horizontal resolution from the European Centre for Medium-Range

140 Weather Forecasts (ECMWF), was also used to examine the dynamical context of the SAT

141 variability. The regional SAT variability can be modulated by the troposphere, through various

142 physical and dynamical processes (e.g. subsidence, advective processes). Therefore, in order

143 to explain the dynamics behind this variability, we analyzed the circulation parameters at two

144 different atmospheric pressure levels: one in the lower troposphere $(850 \mathrm{hPa})$, and another in

145 the upper troposphere $(200 \mathrm{hPa})$.

146 To assess the links between the interannual variability of SAT and the circulation

147 patterns, the time series of climate variables, for every grid point, were detrended by removing 148 the slope of the fitted linear regression (Yadav et al. 2009; Chowdary et al., 2014). Correlation 149 and regression analyses were applied to identify teleconnection patterns between the AP 
temperatures and the global circulations. In addition, a composite analysis was further conducted to assess the interannual variability of SAT in the AP. The ENSO (averaged SST anomalies over the equatorial central Pacific; Niño-3.4), the NAO (difference in normalized SLP over Iceland and Gibraltar; https://crudata.uea.ac.uk/cru/data/nao/) and the AO monthly

154 indices were used to examine the climate variability over the 51-year period.

The ENSO phenomenon, is one of the most important drivers of interannual climate variability in the Pacific, and affects the weather and climate in large parts of the world (e.g. Horel and Wallace, 1981; Ropelewski and Halpert, 1987; Kiladis and Diaz, 1989; Yadav et al., 2009; Chowdary et al., 2014; Hasanean and Almazroui, 2016 ). The North Atlantic Oscillation (NAO) (Walker, 1925) is a dominant mode of atmospheric variability over the North Atlantic and surrounding regions (e.g. Hurrel et al., 2003). It is characterized by a meridional oscillation between the atmospheric mass of the polar low and that of the subtropical high. The positive (negative) phase of the NAO exhibits a deeper (shallower) Icelandic low and a stronger (weaker) subtropical high. NAO exhibits a strong seasonal, interannual and decadal variability,

164 with the largest variability in winter (Hurrel et al., 2003). The Atlantic Oscillation (AO), an 165 indicator of the strength of the circumpolar vortex (Thompson and Wallace, 1998), is another 166 dominant pattern of SLP variation that controls the SAT variability over high and middle 167 latitudes. AO is characterized by SLP anomalies that have one sign in the Arctic, and SLP 168 anomalies of the opposite sign (around $37^{\circ} \mathrm{N}-45^{\circ} \mathrm{N}$ ). The oscillation exhibits a negative phase 169 with a relatively high pressure over the polar region, and low pressure at middle latitudes (about $17045^{\circ} \mathrm{N}$ ), and a positive phase when this pattern is reversed (Thompson and Wallace, 2000; Gong 171 et al., 2001).

\section{3. Results and discussion}

\section{$173 \quad 3.1$ Climatology of SAT}

174 The spatial distribution of mean seasonal temperatures in the AP for the period 1960-2010 is 
175 shown in Fig. 1. During winter (Fig. 1a), SAT is low $\left(<15^{\circ} \mathrm{C}\right)$ over the northern AP, moderate $176\left(15-20{ }^{\circ} \mathrm{C}\right)$ over the central and western AP, and high (up to $20-25{ }^{\circ} \mathrm{C}$ ) over the southeastern 177 AP, suggesting three distinct climate zones characterized in this region. The northern AP is 178 cooler because of the influence of western disturbances originating in the Mediterranean 179 region, whereas the southern AP is considerably warmer because of less rainfall. Additionally, 180 temperature in the southeastern AP is higher than those in the southwestern AP, where low 181 temperatures associated with the local topography are observed (Langodan et al., 2014; 182 Viswanadhapalli et al., 2016; Attada et al. 2018). During spring (Fig. 1b), the SAT increases 183 over the entire AP, but more quickly in the north, settling between 20 and $25^{\circ} \mathrm{C}$, except in the 184 eastern desert region where temperatures vary between 25 and $27^{\circ} \mathrm{C}$. In early summer (Fig. 185 1c), the SAT distribution becomes more uniform across the AP, with the highest temperatures 186 (above $35^{\circ} \mathrm{C}$ ) observed in the eastern region, and the lowest temperatures (around $25^{\circ} \mathrm{C}$ ) over the southern tip of the AP. In summer (Fig. 1d), the SAT patterns are similar to those of early summer (Fig. 1c), but exhibit higher magnitudes. The strong cross-equatorial flow along the coast of Somalia induces upwelling over the western Arabian Sea, which cools the SST and consequently decreases the temperature over the southern tip of AP ( Izumo et al., 2008; Yao and Hoteit, 2015). In autumn (Fig. 1e), moderate SATs ranging from 20 to $25{ }^{\circ} \mathrm{C}$ are observed over the AP. In the northwestern and western AP, the SAT remains below $25{ }^{\circ} \mathrm{C}$ (Fig. 1e), 193 whereas the highest SATs are observed in the eastern AP. The spatial distribution of the annual 194 mean SAT (Fig. 1f) for the entire analysis period shows the highest SATs over the southeastern 195 AP with a maximum around $30{ }^{\circ} \mathrm{C}$, and a minimum value of approximately $21{ }^{\circ} \mathrm{C}$ over the northwestern parts of the AP. Low SATs in the northern coast of Oman appears in all seasons, except summer. Summer high SATs exceeding $30{ }^{\circ} \mathrm{C}$ are observed over the desert areas, and in association with a strong descent motion (Babu et al. 2016; Hasanean and Almazroui 2016). 
the adiabatic warming that favor the higher temperatures (Figure not shown). This descent motion is found to be a consequence of the monsoon-desert mechanism (Rodwell and Hoskins, 1996) and stronger summer solar isolation. The high temperatures favor the formation of thermal lows, which may have increased the cyclonic activities over the AP (El Kenawy et al. $2042014 ; 2016 a)$.

\section{$205 \quad$ 3.2 SAT Variability}

206 The AP interannual SAT standard deviation for each season (Fig. 1; contours) suggests that the 207 winter SATs vary between $0.4{ }^{\circ} \mathrm{C}$ in the south and $1.5{ }^{\circ} \mathrm{C}$ in the north. The intensity of the interannual SAT variability over the central and southwestern AP in spring is found higher than that in winter by about $0.2^{\circ} \mathrm{C}$, whereas the AP in general, has a weaker meridional gradient in 210 spring than in winter. Spatial variations in the standard deviation of SAT, from southeast to northwest are noticeable in the early summer and summer seasons. A general decrease in the magnitude of SAT interannual variability also evident from winter to summer. In autumn, high variability is confined in the eastern, over the United Arab Emirates $\left(0.8^{\circ} \mathrm{C}\right)$ and the northern AP. With respect to the annual SAT, the spatial patterns of the interannual standard deviations are similar to those of seasonal standard deviations, but have lower magnitudes. The above analysis clearly suggests a pronounced regional SAT variability over the 217 AP. The SAT annual cycle is presented in Fig. 2 for the entire AP, the southern AP (SAP; $12-$ $\left.22^{\circ} \mathrm{N}, 35-60^{\circ} \mathrm{E}\right)$ and the northern AP (NAP; $\left.22-32^{\circ} \mathrm{N}, 35-60^{\circ} \mathrm{E}\right)$ AP. The selection of these

219 sub-regions is based on their regional climate characteristics. The NAP is characterized by a 220 low-elevation terrain, and is mainly influenced by mid-latitude circulations, whereas the SAP 221 exhibits a more complex terrain and is influenced by the Indian monsoons (e.g. Almazroui et al. 2013; Athar et al. 2014). The annual cycles of all three regions show a higher SAT from

223 June through September, and a more pronounced thermal gradient between the NAP and the 224 SAP, during winter $\left(6-7^{\circ} \mathrm{C}\right)$. The high temperature gradient observed in winter is due to the 
225 influence of western disturbances originating from the Mediterranean region (e.g. Almazroui et al., 2012, 2013; Athar et al., 2014; Langodan et al., 2017). The weaker gradient of SAT in the SAP, compared with the NAP is due to the influence of the neighboring Arabian Sea SST. We also analyzed the time-latitude variation of SAT (averaged between $35^{\circ} \mathrm{E}-60^{\circ} \mathrm{E}$ ) over the AP (Figure not shown) to examine the seasonal variations. The highest temperatures occur 230 between May and September, within the $19^{\circ}-32^{\circ} \mathrm{N}$ latitude belt, and the lowest temperatures are observed in winter, indicating that the spatial patterns of the AP SAT are predominantly related to seasons.

\subsection{SAT Trends}

234 We further investigate SAT trends for all five seasons, across the AP, with respect to the global 235 SAT trend over the analysis period 1901-2010. The temporal evolution of the seasonal and annual SAT anomalies averaged over the AP are presented in Fig. 3, and the corresponding

237 global trends are presented in Table 1. It is observed (Fig. 3a) that the AP SAT anomaly generally varies between $-1.4{ }^{\circ} \mathrm{C}$ and $0{ }^{\circ} \mathrm{C}$ before the $1940 \mathrm{~s}$. Relatively large values are noticeable in the 1980s, after which temperatures started to rise. In winter (Fig. 3a), both the 240 global SAT and the AP SAT's increased significantly by about $0.09^{\circ} \mathrm{C}$ and $0.07^{\circ} \mathrm{C}$ per decade, suggesting a close relationship between the AP SAT and the global SAT with a significant correlation coefficient (CC) of 0.5 . In spring (Fig. 3b), the AP temperature anomalies also

243 exhibit a warming trend of $0.12{ }^{\circ} \mathrm{C}$ per decade, correlated $(\mathrm{CC}=0.54)$ with the global 244 temperature anomalies, showing a trend of $0.10{ }^{\circ} \mathrm{C}$ per decade. In summer, we observed an 245 abrupt increase in the AP SATs starting from the late 1980s (Fig. 3c and 3d), in agreement with the previously reported results (Almazroui 2006; AlSarmi and Washington 2011). The AP SAT

247 also exhibited a significant warming trend of $0.13{ }^{\circ} \mathrm{C}\left(0.12{ }^{\circ} \mathrm{C}\right)$ per decade, compared to the 248 global trend of $0.07{ }^{\circ} \mathrm{C}\left(0.06^{\circ} \mathrm{C}\right)$ per decade. In early summer and summer, the global and the 249 AP SAT anomalies remain closely correlated, with respective CCs of 0.8 and 0.85 . Autumn 
temperatures (Fig. 3e) also show similar trends over the AP and globally, with a correlation of

251 0.6. The SAT annual mean, Fig. 3(f) suggests a warming trend of $0.10^{\circ} \mathrm{C}$ per decade, over the AP, and $0.08^{\circ} \mathrm{C}$ per decade globally. Overall, the global SAT and the AP SAT show significant increases starting from the 1980s. The rise of the AP SAT is, however, more pronounced than

254 the global mean SAT for all seasons.

Figure 4 plots the time series of detrended air-temperature anomalies (normalized) over the AP for all seasons, revealing that the AP SAT exhibits a clear interannual variability over the study period. The number of anomalous warm years clearly increases from the 1990s onwards. Note that years with greater (lower) than one standard deviation are marked for identification of the warm (cold) events. These events are used to conduct a composite analysis 260 for each season (Fig. 5). Composite anomalies of the winter SAT (Fig. 5a) show a positive warming of $0.5-1.5{ }^{\circ} \mathrm{C}$ for anomalous warm years and negative temperature anomalies $(-0.7$ to $-1.8^{\circ} \mathrm{C}$ ) during the anomalous cold years (Fig. 5b). It is also observed that negative anomalies are more pronounced in the northern region of the AP. In spring (Fig. 5c), a strong warming is

264 noticeable over the northern and northeastern AP, exceeding $1.5^{\circ} \mathrm{C}$ during anomalous warm 265 years, whereas slightly lower temperature anomalies are observed in the southern tip of the AP. 266 Temperature anomalies ranging from -0.9 to $-1.8{ }^{\circ} \mathrm{C}$ are recorded over the central and northern 267 AP during anomalous cold years (Fig. 5d). The warm and cold composites of SAT anomalies 268 appear in opposite phases during spring. The spatial patterns of warming and cooling during 269 early summer (Fig. 5e) are similar to those of observed in spring, but at lower magnitudes. In 270 the warm composite, warming is more pronounced in the northern AP than in the southern AP. 271 Similarly, the cold composites (Fig. 5f) show maximum cooling between the central and the northern AP. The warm and cold composite SAT patterns in summer (Fig. 5g) are almost

273 similar to the early summer patterns, except over the western AP and its adjoining regions, 274 where predominant cooling is found. The warm and cold SAT composites for autumn (Fig. 5i) 
275 show similar patterns to summer, with warm temperature anomalies confined to the northern 276 region, and relatively weaker warm anomalies in the southern AP. With respect to the cold

277 SAT composites (Fig. 5j), negative temperature anomalies are observed across the AP with 278 more cooling over the northeastern AP. Overall, anomalous high temperatures can have 279 adverse impacts on water resources, agriculture and crop yields. This variability of warm and 280 cold SAT may also have a strong impact on the regional climate (e.g. Chowdary et al., 2014), 281 reinforcing the importance of understanding the plausible causes of the interannual SAT 282 variability for different seasons.

\section{Links of SAT to dominant circulation patterns}

\subsection{Relationship of SAT with SST and Atmospheric Circulation}

285 To investigate the relationship between the SAT over the AP and the global SST, the spatial 286 correlation coefficient between the first mode of the principal component analysis (PCA) of the AP SAT and the SST anomalies for the1960-2010 period, and for each season, are presented in Fig. 6. The PCA is a multivariate statistical variable-reduction procedure, commonly used to extract the leading spatial patterns of climate variability (e.g. Wilks 2011). In our study, we found that the major PCA mode (PC1) contributes more than $80 \%$ of the total variance, and correlates with the global SSTs. The winter correlation (Fig. 6a) is significantly positive between the AP and SST over the northern Arabian Sea, the equatorial western Pacific Ocean and the equatorial and North Atlantic Ocean, suggesting a relationship between the tropical oceans and the AP SAT during this season. In spring (Fig. 6b), significant positive correlations are observed over the northern Indian Ocean, equatorial Atlantic Ocean and the western tropical Pacific Ocean (known as the warm pool region), whereas significant negative correlations are noticeable over the eastern Pacific Ocean. The spring correlations also suggest that the AP SAT is strongly influenced by the western Pacific region and the Indian Ocean. 
We found that early summer air temperature over the AP has a significant positive relationship with the western tropical Pacific Ocean and the Atlantic Ocean (Fig. 6c), whereas the north Pacific Ocean SSTs are negatively correlated with the AP SAT. In summer, the AP air temperature also exhibits a significant positive relationship with the northern Arabian Sea, the Mediterranean Sea, the western Pacific Ocean and the equatorial Atlantic Ocean (Fig. 6d).

304 This positive correlation exceeds 0.5 (significance at the $99 \%$ confidence level) over wide 305 regions of the Atlantic Ocean, suggesting that the AP SAT variability during summer is related to the Indo-Pacific warm pool, which is consistent with the results of Hasanean and Almazroui (2016). In autumn, the AP SAT is correlated with the Northern Indian Ocean and the equatorial 308 Atlantic Ocean (Fig. 6e). We also computed the spatial correlation coefficient between the 309 NAP and SAP SATs with the SST anomalies (not shown). In all seasons, the SAP surface temperatures are strongly correlated with the western Indian Ocean SSTs. During autumn, the

311 ENSO impact on the SAP temperature variability becomes more important, whereas the impact 312 of the Indian Ocean weakens. The NAP SAT variability seems to be mostly controlled by the 313 Atlantic Ocean and Mediterranean Sea as a result of western disturbances. Overall, the PC1 314 correlation with global tropical SST suggests that in all seasons AP SAT is strongly influenced by the Atlantic warm SSTs. The North Indian Ocean SST impact on AP (PC1) SAT is high in DJF, MA and ON seasons. Moreover, the equatorial western Pacific SST also displays a strong 317 relationship with the first mode of AP SAT in all seasons, expect in ON. This analysis suggests 318 that SST variations over the equatorial Atlantic, western Pacific and north Indian Ocean have 319 a considerable impact on the AP temperature.

We further investigate the dominant atmospheric configurations associated with the

321 SAT variability. Figure 7 depicts the spatial correlation coefficients between the AP SAT and 322 MSLP, and the regression of the AP SAT with low-level (850 hPa) winds for different seasons. 323 During winter (Fig. 7a), the correlation of MSLP with the AP SAT (shaded) shows significant 
negative correlations over North Africa, Europe and the North Atlantic Ocean, the Mediterranean Sea, with small regions of positive MSLP anomalies over the Tibet and higher latitudes. The negative MSLP anomalies over the North Atlantic Ocean and positive anomalies at higher latitudes resemble the NAO and AO patterns. The regression of low-level circulation against the AP SAT reflects the anomalous cyclonic circulation over the Mediterranean Sea and the North Atlantic Ocean associated with lower SLP anomalies. Westerly wind anomalies blowing from the North Atlantic Ocean through North Africa converge with weak easterly wind anomalies from the western Indian Ocean to blow north toward the AP. The anomalous lower tropospheric westerly winds travel through the Sahara (hot deserts) and influence the

333 SAT variability over the AP during winter.

In spring (Fig. 7b), negative SLP anomalies and anomalous cyclonic circulation prevail over the North Atlantic Ocean (Azores region), while easterlies dominate the southern Arabian region. The AP SAT exhibits a significant positive correlation with the atmospheric circulation over Siberia. Northeasterly wind anomalies blow from India into the AP, suggesting that spring temperature variability over the AP is associated with a Siberian high and an Azores low.

339 Similarly, in early summer (Fig. 7c), the AP SAT shows an anomalous cyclonic circulation over the southern AP and the Atlantic region, and is positively correlated with East Asia. In

341 summer (Fig. 7d), the AP SAT appeared strongly and positively correlated with Siberia, the 342 Indian subcontinent and East Asia, but negatively correlated with the Saharan heat low and the 343 equatorial Atlantic Ocean. The AP SAT regression onto the low-level winds shows a cyclonic 344 circulation over North Africa, particularly over the Sahara and the western Mediterranean regions, consistent with negative SLP anomalies. This suggests the intensification of a heat low over the Sahara, one of the components of the summer West African monsoon system, and the

347 influence of North Africa on the AP SAT. Easterly wind anomalies from the equatorial Indian 348 Ocean and westerly wind anomalies from Africa tend to converge and move towards the AP 
region.

In autumn (Fig. 7e), strong negative correlations are observed over the Sahara and

North Africa compared to summer. The increase in SAT over the AP due to the intensification of the Saharan heat low and the associated cyclonic circulation anomaly is noticeable over North Africa and the Saharan heat-low region. Strong positive SLP anomalies are also observed over the Tibet and the western Pacific warm pool region. The low-level easterly anomalies persist and move towards the Saharan heat-low region from the southern AP, which could potentially influence the SAT. In summary, the anomalous low pressures over the North Atlantic and the Sahara and the high pressures over Siberia and the warm pool region drive a warmer SAT over the AP. During winter, the low pressure anomaly over the North Atlantic dominates but, as the summer progresses, the high pressure anomaly of the warm pool region takes over the North Atlantic anomaly and dominates the AP SAT.

To further investigate how the AP SAT can be influenced by large-scale atmospheric circulation, the correlation and regression of the AP SAT with the upper-level zonal winds (U200) have been examined for all seasons over the period 1960-2010. In winter (Fig. 8a), significant positive correlations are observed over the Mediterranean region. These positive correlations are zonally elongated at around $30^{\circ} \mathrm{N}$, from the West Asia, North Pacific and North Atlantic regions. Significant negative zonally elongated correlations north of $55^{\circ} \mathrm{N}$ and equatorial Atlantic Ocean correlations also appear over the AP, and extend up to Iran. This is related to the weakening of the Asian subtropical westerly jet stream (STJ) over the Middle

369 East, and an increase in the AP SAT. We found this dampening of the STJ to be associated with weak western disturbances, which favor drought conditions in the AP.

372 the positive zonal wind anomalies over the Somali coast, the negative anomalies over the AP 373 and the positive anomalies over the Mediterranean region. Similar patterns of anomalous highs 
374 and lows are visible in the upper-level geopotential heights (Figure not shown). Yadav et al. 375 (2009) demonstrated that the upper troposphere is the most important region for Rossby wave 376 propagation in the tropical and subtropical regions. This suggests that during winter, the AP 377 SAT variability is related to the STJ, the Middle East jet stream and Rossby wave train-type 378 patterns.

In spring (Fig. 8b), the AP SAT exhibits significant positive correlation patterns over the Mediterranean, Europe, East Asia, the North Pacific and the North Atlantic regions, whereas strong negative correlations are observed over the Middle East, equatorial Atlantic regions and the equatorial Indian Ocean. In early summer (Fig. 8c), the AP surface temperature 383 is significantly positively correlated with U200 anomalies over central Asia and Northern 384 Europe, and is negatively correlated with the northern Caspian Sea, the Mediterranean Sea and 385 North Asia. The AP SATs are also influenced by meridional Rossby wave patterns in the upper troposphere. In summer (Fig. 8d), the AP SAT is strongly correlated with U200 anomalies over the Iran region and Eastern Asia. It is interesting to note that the Asian jet is weakening in the summer, which may closely relate to the increasing AP SAT. During autumn (Fig. 8e), strong positive correlations are noticeable from the Middle East to East Asia, in the northeastern Pacific region and in the North Atlantic region; significant negative correlations are noticeable over the Mediterranean Sea, the Caspian Sea and China. The AP SAT also exhibits a significant negative correlation with the eastern and central Pacific regions, indicating that autumn temperatures over the AP are related to the Asian STJ, the central and equatorial Pacific easterlies and the circumpolar westerlies. There are significant positive correlations over the Indian Ocean, the tropical western Pacific, the high latitudes of the North Pacific and the middle and low latitudes of the Atlantic. It is also observed that the areas with the maximum anomalies in temperature are consistent with the areas containing the maximum anomalies in geopotential 398 height (Figure not shown). These results outline the potential effect of the large-scale 
circulations on the AP SAT variability through the modulation of jet streams and the Rossby wave train-type patterns.

\subsection{AP SAT and Large-Scale Climate Drivers}

The large-scale climate drivers, ENSO, NAO and AO, play a significant role in modulating the regional temperature variations of the Northern Hemisphere. Here, we evaluate the relationship between these large-scale climate drivers and the AP SAT.

\subsubsection{Relationship with ENSO}

407 The correlation coefficient between the AP SAT and the Niño 3.4 SST index (ENSO index) 408 during winter is plotted in Fig. 9a; in this figure, we clearly see a significant positive correlation $409(\mathrm{CC}=0.5)$ between ENSO and SAT over the southern part of the AP, and a significant negative correlation over the Sudan region. The warm phases of ENSO (El Niño) could trigger warm surface temperatures over the southern tip of the AP during winter. No significant correlations are observed in the central and northern AP SAT. During spring (Fig. 9b), ENSO exhibits a significant negative correlation with north Africa, Egypt and northern AP regions. In early

414 summer (Fig. 9c), ENSO and AP SAT do not seem to be correlated, except over the central AP and Oman region. ENSO exhibits a significant positive correlation with east Africa and Sahel region. In summer, ENSO is positively correlated with the southwestern AP, Oman and Africa regions. In autumn (Fig. 9e), the central and southern AP SAT are significantly and positively correlated with ENSO, at a 95\% confidence level. The correlation between ENSO and the annual mean SAT (Fig. 9f) over the AP shows similar patterns during the winter season (Fig.

420 9a). In summary, the warm phase of ENSO seems to mainly impact the southern AP, with a significant positive correlation with that region. ENSO may thus cause more temperature extremes (Donat et al. 2014) that accentuated the aridity conditions over the AP (El Kenawy et al. 2016b). 

the period 1960-2010 is illustrated in Fig. 10. During winter, high negative correlations $(\mathrm{CC}=$

427 -0.8) are observed in the AP, north Africa (Fig. 10a) significant at a 95\% confidence level, 428 indicating lower AP surface temperatures during the negative phases of NAO. In spring (Fig. 429 10b), significant negative correlations appear mostly in the AP similarly what was observed 430 during winter. In early summer (Fig. 10c), the strong negative correlation between NAO and 431 SAT expands towards the north and the northeast AP. In summer, strong negative correlations $432(\mathrm{CC}=-0.8)$ over the northern AP, the central AP and Caspian Sea are also noticeable (Fig. 433 10d), whereas strong positive correlations are found over eastern Iran. Autumn (Fig. 10e) 434 exhibits moderate negative correlations over the northern AP region but strong negative 435 correlations are noticeable over the north of the region. No significant correlations are observed 436 in the central or southern AP, or along the coast of the Red Sea. The spatial correlations of the 437 annual mean SAT exhibits similar patterns to those of the winter season (Fig. 10f). The negative 438 phase of NAO clearly had a strong influence on surface temperatures over the northern AP, 439 Iran and Pakistan. Overall, it appears that NAO has strong relation with the AP SAT in the 440 northern AP during winter. The negative correlation indicates that during the negative phase 441 of NAO, the temperature over the AP tends to increase, whilst during the positive phase of the

$442 \mathrm{NAO}$, the mean temperature tends to decrease over the region, which is consistent with an 443 earlier study by Donat et al. (2014). Overall, our results emphasize the fact that the interannual 444 surface temperature variability over the AP has a strong relationship with NAO during winter 445 in comparison with other seasons. El Kenawy et al. (2016b) also confirmed that the links 446 between the NAO and Middle East climate are best expressed during winter time, compared 447 with the other seasons.

\section{$448 \quad$ 4.2.3 Relationship with AO}


450 AP SAT $(\mathrm{CC}=0.9)$, suggesting that $\mathrm{AO}$ is an important climate driver of the AP SAT 451 variability. Specifically, correlations over the central and northern AP exceed 0.8, a higher than 452 that of the ENSO (Fig. 9a) and NAO (Fig. 10a) indices. During spring (Fig. 11b) and early 453 summer (Fig. 11c), AO and AP SAT do not seem to be correlated except over the Yemen 454 region. In summer (Fig. 11d), moderate negative correlations $(\mathrm{CC}=0.4)$, is observed between 455 AO and the AP SAT. However, significant positive correlations are observed over the northern 456 Pakistan and adjacent regions. In autumn (Fig. 11e), negative correlations reappear in the 457 northern AP, as observed in spring but with higher correlations. Annual mean temperatures 458 exhibited significant negative correlations with AO over the northern AP (Fig. 11f). Our 459 analysis clearly indicate that the AP SAT is strongly related to the negative phases of AO and 460 NAO teleconnections, while ENSO's influence is limited to the southern AP SAT. Therefore, 461 AO and NAO may be used as good indicators of the mean surface temperature over the AP. 462 These results clearly suggest that the SAT variability of the AP is influenced by the tropical 463 SSTs on an interannual time scale, and are consistent with previous studies by Hasanean (2005) 464 and Hasanean and Almazroui (2016). The above analysis suggests that the negative modes of NAO and AO are the key 466 controllers of the SAT variability in the region. We thus further investigated the SLP variations 467 associated with the negative modes of NAO and AO, for all seasons (Fig. 12). We found that the composite of SLP during the negative phases of NAO and AO are characterized by positive 469 SLP anomalies over Iceland, and negative SLP anomalies over the Azores High, for all seasons, 470 except summer (which exhibit weaker anomalies). The negative phase of AO/NAO decreases 471 the pressure gradient between the extra-tropical and polar north Atlantic, resulting in a 472 weakening of the Asian westerly jet stream over North Africa and the Middle East (De Vries 473 et al. 2018). This decreases the number of western disturbances, causing less precipitation and 474 increasing the temperatures over the AP (Yadav et al. 2009; De Vries et al. 2013). Moreover, 
475 a negative SLP anomaly over the Azores High induces a cyclonic circulation over the 476 subtropical Atlantic region, whereas the southern flank of the anomalous cyclonic circulation

477 induces westerlies. These anomalous lower tropospheric westerly winds originating from the 478 warm tropical Atlantic and traveling through the hot deserts (entire North Africa region) advect 479 warm temperatures towards the AP and increase its temperatures, suggesting the important role 480 of the negative modes of $\mathrm{NAO}$ and $\mathrm{AO}$ in modulating temperatures of the AP.

\section{Summary}

483 This study investigated the long-term variability of the SAT over the AP, using CRU gridded 484 data over the period of 1960-2010. The main findings of this study can be summarized as 485 follows:

- The seasonal mean AP SATs are stronger during summer. The interannual variability of $487 \quad$ SAT over the northern AP is stronger during winter.

- The annual cycle of regional SAT shows that the thermal gradient between the northern and 489 southern AP is more pronounced in winter $\left(6-7{ }^{\circ} \mathrm{C}\right)$, due to the influence of western 490 disturbances originating from the Mediterranean Sea.

- A linear trend analysis revealed a significant increase of SAT anomalies over the AP, with 492 more frequent extreme hot events in recent decades.

- SST variations over the equatorial Atlantic, western Pacific and north Indian Ocean have a 494 considerable impact on the AP SATs.

- The negative SLP anomalies over the North Atlantic, and the positive anomalies at higher 496 latitudes, resemble the NAO and AO patterns. Lower-tropospheric anomalous westerly 497 winds travel through the hot African deserts to influence the AP SAT variability during 498 winter. 
499

500

501

502

503

504

505

506

507

508

509

510

511

\section{Acknowledgments}

518 The research reported in this publication was supported by King Abdullah University of 519 Science and Technology (KAUST), Saudi Arabia and the Saudi ARAMCO-KAUST Marine

520 Environmental Research Center (SAKMERC). The authors thank the anonymous reviewers

521 for the insightful comments on the manuscript.

- In summer, the SAT variability over the AP is dominated by the heat low over the Sahara and North Africa, the easterly wind anomalies blowing from the equatorial Indian Ocean, and the westerly wind anomalies from Africa.

- The correlations of the AP SAT with the upper-level zonal winds during winter suggests that the intensification of the Asian subtropical westerly jet stream (STJ) and the Middle East jet stream are closely related with the increase in the AP SAT.

- The regression of U200 onto the AP SAT outlines positive zonal wind anomalies over the Somali coast, negative anomalies over the AP, positive anomalies over the Mediterranean region, implying a Rossby wave train. Our analysis suggests that large-scale circulation patterns may impact on the AP SAT variability through modulation of jet streams and Rossby wave train-type patterns.

Our study further emphasizes that the wide variability of the AP SAT is closely associated with the climate drivers of ENSO, AO and NAO. Overall, when considering these large-scale teleconnections, we find that the NAO and AO dominate the AP SAT variability during winter, whereas ENSO dominates the southern AP SAT variability in summer, winter and autumn. Future studies need to focus on the underlying physical processes explaining the links to largescale circulation patterns over this region.

522 
523

Abdulrazzak, MJ. and M. Z. A. Khan, (1990) Domestic Water Conservation Potential in Saudi Arabia. Environmental Management 14:167-178.

Abualnaja, Y., Papadopoulos, VP., Josey, SA., Hoteit, I., Kontoyiannis, H., and Raitsos, DE. (2015) Impacts of climate modes on air-sea heat exchange in the Red Sea, J. Clim., 28, 2665-2681, doi:10.1175/JCLI-D-14-00379.1.

Alexander LV, Zhang X, Peterson TC, Caesar J, Gleason B, Klein Tank A, Haylock M, Collins D, Trewin B, Rahimzadeh F, Tagipour A, Ambenje P, Rupa Kumar K, Revadekar J, Griffiths G, Vincent L, Stephenson D, Burn J, Aguilar E, Brunet M, Taylor M, New M, Zhai P, Rusticucci M, Vazquez-Aguirre JL. (2006) Global observed changes in daily climate extremes of temperature and precipitation J. Geophys. Res., 111: D05109, DOI:10.1029/2005JD006290.

Alghamdi AS, and Moore TW. (2014) Analysis and comparison of trends in extreme temperature indices in Riyadh City, Kingdom of Saudi Arabia, 1985-2010, J. Climatol., 2014(1), 1-10.

Alkolibi FM. (2002) Possible effects of global warming on agriculture and water resources in Saudi Arabia: Impacts and responses. Climatic Change, 54: 225-245.

Almazroui M. (2006) The Relationship Between Atmospheric Circulation Patterns and Surface Climatic Elements in Saudi Arabia, PhD thesis, Climate Research Unit, University of East Anglia.

Almazroui M, Islam MN, Jones PD, Athar H, Rahman MA. (2012) Recent climate change in the Arabian Peninsula: seasonal rainfall and temperature climatology of Saudi Arabia for 19792009. Atmos. Res. 111:29-45. doi:10.1016/j.atmosres.2012.02.013.

Almazroui M, Hasanean, HM., Al-Khalaf, AK., Abdel Basset, H. (2013) Detecting climate change signals in Saudi Arabia using mean annual surface air temperatures. Theor. Appl. Climatol., $113,585-598$.

Almazroui, M., Islam, MN., Dambul, R. and Jones, PD. (2014) Trends of Temperature Extremes in Saudi Arabia. Int. J. Climatol., 34, 808-826. http://dx.doi.org/10.1002/joc.3722.

Almazroui M, Dambul R, Islam N, Jones PJ (2015) Atmospheric circulation patterns in the Arab region and its relationships with Saudi Arabian surface climate: a preliminary assessment. Atmos Res 161-162: 36-51.

Almazroui, M. (2016) RegCM4 in climate simulation over CORDEX-MENA/Arab domain: selection of suitable domain, convection and land surface schemes. Int. J. Climatol., 36, pp. 236-351 http://dx.doi.org/10.1002/joc.4340.

AlSarmi S, Washington R. (2011) Recent observed climate change over the Arabian Peninsula. J. Geophys. Res. 116: D11109, DOI:10.1029/2010JD015459. 
AlSarmi S, Washington R. (2014) Changes in climate extremes in the Arabian Peninsula: analysis of daily data. Int. J. Climatol., 34: 1329-1345, DOI: 10.1002/joc.3772

Al-Zahrani, K. H. (2010) Water Demand Management in the Kingdom of Saudi Arabia. Conference of International Journal of Art \& Science, 2, 68-76.

Al-Zahrani KH, Baig MB (2011) Water in the Kingdom of Saudi Arabia: sustainable management options. J Animal Plant Sci 21(3):601-604

Athar H., (2012) Decadal variability of the observed daily temperature in Saudi Arabia during 19792008. Atmos. Sci. Lett., 13 , pp. 244-249 doi:10.1002/asl.390.

Athar, H. and Ammar, K. (2016) Seasonal characteristics of the large-scale moisture flux transport over the Arabian Peninsula. Theor. Appl. Climatol., 124: 565. doi:10.1007/s00704-015-1437-7.

Attada R, Dasari HP, Parekh A, and Chowdary JS, and Langodan S, and Knio O, and Hoteit I (2018) The role of the Indian Summer Monsoon variability on Arabian Peninsula summer climate. Clim Dyn., doi: 10.1007/s00382-018-4333-x, in press.

Babu CA, Jayakrishnan PR, Varikoden H. (2016) Characteristics of precipitation pattern in the Arabian peninsula and its variability associated with ENSO. Arab. J. Geosci. 9: 186.

Bannayan M., Sanjani, S., Alizadeh, A., Lotfabadi, SS., Mohamadian, A. (2010) Association between climate indices, aridity index, and rainfed crop yield in northeast of Iran. Field Crops Res 118: $105-114$.

Chowdary JS, John N, Gnanaseelan C. (2014) Interannual variability of surface air-temperature over India: impact of ENSO and Indian Ocean sea surface temperature. Int. J. Climatol., 34(2): 416429, doi: 10.1002/joc.3695.

Cullen, HM., Kaplan, A., Arkin, P., and de Menocal, PB. (2002). Impact of the North Atlantic oscillation on Middle Eastern climate and stream flow. Clim. Change., 55, 15338.doi:10.1023/A:1020518305517.

Dabour, N. (2006) "Water Resources and their Use in Agriculture in Arab Countries." Journal of Economic Cooperation 27(1): 1-38.

Dasari, HP., S. Langodan, Y. Viswanadhapalli, B. R. Vadlamudi, V. P. Papadopoulos, and I. Hoteit (2017) ENSO influence on the interannual variability of the Red Sea convergence zone and associated rainfall, Int. J. Climatol., doi:10.1002/joc.5208, in press. 
de Vries A. J., Ouwersloot, H. G., Feldstein, S. B., Riemer, M., El Kenawy, A. M., McCabe, M. F., \& Lelieveld, J. (2018) Identification of tropical-extratropical interactions and extreme precipitation events in the Middle East based on potential vorticity and moisture transport. Journal of Geophysical Research: Atmospheres, 123, 861-881. https://doi.org/10.1002/2017JD027587.

Donat M G, Peterson TC, Brunet M et al., (2014) Changes in extreme temperature and precipitation in

595

596

597

598

599

600

601

602

603

604

605

606

607

608

609

610

611

612

613

614

615

616

617

618

619

620

621 the Arab region: Long-term trends and variability related to ENSO and NAO. Int. J. Climatol., 34(3): 581-592.

El Kenawy AM, McCabe MF, Stenchikov G, Raj J. (2014) Multi-decadal classification of synoptic weather types, observed trends and links to rainfall characteristics over Saudi Arabia. Front Environ Sci 2: 37.

El Kenawy AM, McCabe MF. (2016a) A multi-decadal assessment of the performance of gauge- and model-based rainfall products over Saudi Arabia: climatology, anomalies and trends. Int. J. Climatol. 36: 656-674. https://doi.org/10.1002/joc.4374.

El Kenawy AM, McCabe MF, Vicente-Serrano SM, Robaa SM, Lopez-Moreno JI (2016b) Recent changes in continentality and aridity conditions over the Middle East and North Africa region, and their association with circulation patterns. Clim Res 69:25-43. https://doi.org/10.3354/cr01389.

Fernández-Montes S, Rodrigo FS. (2011) Trends in seasonal indices of daily temperature extremes in the Iberian Peninsula, 1929-2005. Int. J. Climatol. 32: 2320-2332, DOI: 10.1002/joc.3399.

Gámiz-Fortis S.R., Esteban-Parra MJ., Pozo-Vázquez D. and Castro-Díez Y. (2011) Variability of the monthly European temperature and its association with the Atlantic sea-surface temperature from interannual to multidecadal scales. Int. J. Climatol., 31, 2115-2140.

Ghasemi AR, Khalili D (2006) The influence of the Arctic Oscillation on winter temperatures in Iran. Theor Appl Climatol., 85:149-164.

Gong, D.-Y., Wang, S.-W., and Zhu, J.-H. (2001) East Asian winter monsoon and Arctic Oscillation. Geophys. Res. Lett., 28, 2073-2076.

Hafez Y. (2016) Study on the Relationship between the Oceanic Nino Index and Surface Air Temperature and Precipitation Rate over the Kingdom of Saudi Arabia, Journal of Geoscience and Environment Protection, 4, 146-162.

Harris, I., Jones, PD., Osborn, TJ., and Lister, DH. (2014) Updated high-resolution grids of monthly climatic observations-The CRU TS 3.1 dataset. Int. J. Climatol., doi:10.1002/joc.3711.

Hasanean HM. (2004) Wintertime surface temperature in Egypt in relation to the associated 
623 Hasanean HM, Abdel Basset H. (2006) Variability of summer temperature over Egypt. Int. J. Climatol. 26: $1619-1634$.

Hasanean HM, and Alkhalaf AK. (2012) Variability of wintertime surface air temperature over the Kingdom of Saudi Arabia, Atmospheric and Climate Sciences, Vol. 2, pp. 307-321.

Hasanean HM, and Almazroui M. (2016) Teleconnections of the tropical sea surface temperatures to the surface air temperature over Saudi Arabia in summer season, Int. J. Climatol. DOI: $10.1002 /$ joc. 4758 .

630 Hatzaki M, Flocas HA, Asimakopoulos DN, Maheras P. (2007) The eastern Mediterranean teleconnection pattern: identification and definition. Int. J. Climatol., 27(6): 727-737.

Horel JD, Wallace JM. (1981) Planetary-scale atmospheric phenomena associated with the SouthernOscillation. Mon. Wea. Rev., 109: 813-829.

Huang, B., V. Banzon, E. Freeman, J. Lawrimore, W. Liu, T. Peterson, T. Smith, P. Thorne, S. Woodruff, and Zhang, H. (2015) Extended Reconstructed Sea Surface Temperature version 4 (ERSST.v4), Part I. Upgrades and intercomparisons, J. Clim., 28, 911-930, doi:10.1175/JCLID-14-00006.1.

Hurrell, J. W., Y. Kushnir, G. Ottersen, and Visbeck M. (2003) The North Atlantic Oscillation: Climatic 640 Significance and Environmental Impact, Geophys. Monogr. Amer. Geophys. Union, 134, 279 pp.

IPCC. (2007). Summary for Policymakers. In Climate Change 2007: The Physical Science Basis. Contribution of Working Group I to the Fourth Assessment Report of the Intergovernmental

IPCC, (2013). Summary for Policymakers. In Climate Change 2013: The Physical Science Basis. Panel on Climate Change. Solomon S, Qin D, Manning M, Chen Z, Marquis M, Averyt KB, Tignor M. Miller HL (eds). Cambridge University Press: Cambridge, United Kingdom and New Contribution of Working Group I to the Fifth Assessment Report of the Intergovernmental Panel on Climate Change, Stocker, T., F., Qin, D., Plattner, G-K., Tignor, M., Allen, S. K., Arabian Sea upwelling in Indian monsoon rainfall variability. J. Clim., 21:5603-5623. 
Kiladis GN, Diaz HF. (1989) Global climatic anomalies associated with extremes in the Southern Oscillation. J. Clim., 2:1069 - 1090.

658

659

660

661

662

663

664

665

666

667

668

669

670

671

673

674

675

676

677

678

679

680

681

682

683

684

685

686

Köppen, W. (1936) Das geographische system der klimate. In: Köppen, W. and Geiger, R. (eds) Handbuch der klimatologie. Berlin, Germany: Gebrueder Borntraeger, pp. 1-46.

Kothawale DR, Munot AA, Krishna KK. (2010) Surface air temperature variability over India during 1901 - 2007, and its association with ENSO. Clim. Res., 42: 89 - 104, DOI: 10.3354/cr00857.

Langodan S, Cavaleri L, Yesubabu V, Hoteit I. (2014) The Red Sea: a natural laboratory for wind and wave modeling. J. Phys. Oceanogr. 44: 3139-3159, doi: 10.1175/JPO-D-13-0242.1.

Langodan S, Pomaro A, Cavaleri L, Vishwanadhapalli Y, Bertotti L, and Hoteit I. (2017) The climatology of the Red Sea - Part -I: The wind. Int. J. Climatol., doi: 10.1002/joc.5103.

Lanzante JR. (1996) Lag relationships involving tropical SSTs. J. Clim. 9: 2568-2578.

Lelieveld J, Hadjinicolaou P, Kostopoulou E, Chenoweth J, Giannakopoulos C, Hannides C, Lange MA, El Maayar M, Tanarhte M, Tyrlis E, Xoplaki E. (2012) Climate change and impacts in the Eastern Mediterranean and the Middle East. Climatic Change, 114: 667-687. doi: 10.1007/s10584-012-0418-4.

Merrifield, A., and Xie, S. (2016) Summer U.S. Surface Air Temperature Variability: Controlling Factors and AMIP Simulation Biases. J. Clim. doi:10.1175/JCLI-D- 15-0705.1, in press.

Nasrallah, H., Balling, R. (1993) Spatial and temporal analysis of Middle Eastern temperature changes. Clim Change, 25: 153-161.

Poli P, Hersbach H, Dee D, Berrisford P, Simmons A, Vitart F, Laloyaux P, Tan D, Peubey C, Thépaut J-N, Trémolet Y, Holm E, Bonavita M, Isaksen L, Fisher M. (2016) ERA-20C: An atmospheric reanalysis of the $20^{\text {th }}$ century. J. Clim., 29, 4083-4097, doi:10.1175/JCLI-D-15-0556.1.

Rodwell, MJ., and Hoskins, BJ. (1996) Monsoons and the dynamics of deserts. Quart. J. Roy. Meteor. Soc., 122, 1385-1404.

Rogers, P., and P. Lydon, Eds., (1994) Water in the Arab World: Perspectives and Prognoses. Harvard University Division of Applied Sciences, 369 pp.

Ropelewski CF, Halpert MS. (1987) Global and regional scale precipitation patterns associated with El-Niño/Southern oscillation. Mon. Wea. Rev., 115:1606-1626.

Roxy, MK., Ritika, K., Terray, P., and Masson, S. (2014) The curious case of Indian Ocean warming, J. Clim., 27(22), 8501-8509.

Segele, ZT., Lamb, PJ., Leslie, LM. (2009) Large-scale atmospheric circulation and global sea surface 
687

688

689

690

691

692

693

694

695

696

697

698

699

700

701

702

703

704

705

706

707

708

709

710

711

712

713

714

715

716

717

718

719

\section{5}

718

temperature associations with Horn of Africa June-September rainfall. Int. J. Climatol., 29:1075-1100.

Smith, TM., Reynolds, RW., Peterson, TC., and Lawrimore, J. (2008) Improvements to NOAA's historical merged land - ocean surface temperature analysis (1880-2006). J. Clim., 21, 22832296, doi:10.1175/2007JCLI2100.1.

Tanarhte, M., Hadjinicolaou, P., Lelieveld, J. (2012) Intercomparison of temperature and precipitation data sets based on observations in the Mediterranean and the Middle East. J. Geophys. Res., 117: D12102. DOI: 10.1029/2011JD017293.

Thompson, DW., and Wallace, JM. (1998) The Arctic Oscillation signature in the wintertime geopotential height and temperature fields. Geophys. Res. Lett., 25, 1297-1300, doi:10.1029/98GL00950.

Thompson, DW., and Wallace, JM. (2000) Annular modes in the extratropical circulation. Part I: Month-to-month variability. J. Clim., 13, 1000-1016.

Vinnikov KY, Groisman PY, Lugina KM. (1990) Empirical data on contemporary global climate changes (temperature and precipitation). J. Clim., 3:662-677.

Viswanadhapalli Y, Dasari HP, Langodan S, Challa VS, Hoteit I. (2016) Climatic features of the Red Sea from a regional assimilative model. Int. J. Climatol., http://dx.doi.org/10.1002/joc.4865.

Walker, GT. (1925) Correlation of seasonal variations in weather IX: a further study of world weather, Mem. Indian. Meteor. Dep., 24, 275-332.

Wilks D (2011) Statistical Methods in the Atmospheric Sciences. Academic Press, USA, p 704

World Bank, "Making the most of scarcity: Accountability for better water management results in the Middle East and North Africa Report”, 2010.

Yadav RK, Rupa Kumar K, Rajeevan M. (2009) Increasing influence of ENSO and decreasing influence of $\mathrm{AO} / \mathrm{NAO}$ in the recent decades over northwest India winter precipitation. J. Geophys. Res., 114:D12112, doi:10.1029/2008JD011318.

Yao F and Hoteit I. (2015) Thermocline regulated seasonal evolution of surface chlorophyll in the Gulf of Aden. PLoS ONE, 10, http://dx.doi.org/10.1371/journal.pone.0119951.

7 


\section{List of Figures:}

Figure 1. Seasonal and annual mean surface air temperature $\left({ }^{\circ} \mathrm{C}\right.$, shaded) and standard deviation (contours) over the Arabian Peninsula for the period 1960-2010.

Figure 2. Annual cycle of surface air temperature $\left({ }^{\circ} \mathrm{C}\right)$ over the northern Arabian Peninsula $\left(22-32^{\circ} \mathrm{N}, 35-60^{\circ} \mathrm{E}\right)$, the southern Arabian Peninsula $\left(12-22^{\circ} \mathrm{N}, 35-60^{\circ} \mathrm{E}\right)$ and the whole Arabian Peninsula (12-32 $\left.{ }^{\circ} \mathrm{N}, 35-60^{\circ} \mathrm{E}\right)$ for the period 1960-2010. Vertical bars indicate standard deviation values.

Figure 3. Time series of seasonal and annual mean air temperature anomalies (relative to the mean of 1961-1990) over the globe (red), northern hemisphere (purple) and the Arabian Peninsula (black) during the period 1901-2010. Positive (neg ative) anomalies are shown in red (blue).

Figure 4. Seasonal variations of detrended air temperature anomalies $\left({ }^{\circ} \mathrm{C}\right)$ in the AP during the period 1901-2010.

Figure 5. Composite of air temperature anomalies $\left({ }^{\circ} \mathrm{C}\right)$ for warm years (left) and cold years (right) during DJF, MA, MJ, JAS and ON.

Figure 6. Spatial maps of correlations between the PC1 of the AP surface temperature and the global sea surface temperature for the period of 1960-2010. Area of 95\% significant level is shaded; area of 99\% significant level is contoured.

Figure 7. Spatial maps of correlations between the AP SAT and MSLP (hPa; shaded); regression of low-level $(850 \mathrm{hPa})$ winds $\left(\mathrm{ms}^{-1}\right.$; vectors $)$ with AP SAT for the period 1960-2010.

Figure 8. Same as Figure 7 but for upper-level $(200 \mathrm{hPa})$ winds $\left(\mathrm{ms}^{-1}\right)$. Correlation is shaded and regression is contoured.

Figure 9. Horizontal distribution of the correlation coefficient between the ENSO index and the APSAT.

Figure 10. Same as Figure 9 but for NAO index.

Figure 11. Same as Figure 9 but for AO index.

Figure 12. Spatial patterns of sea level pressure anomalies during negative modes of NAO (left panel) and AO (right panel) for different seasons. 

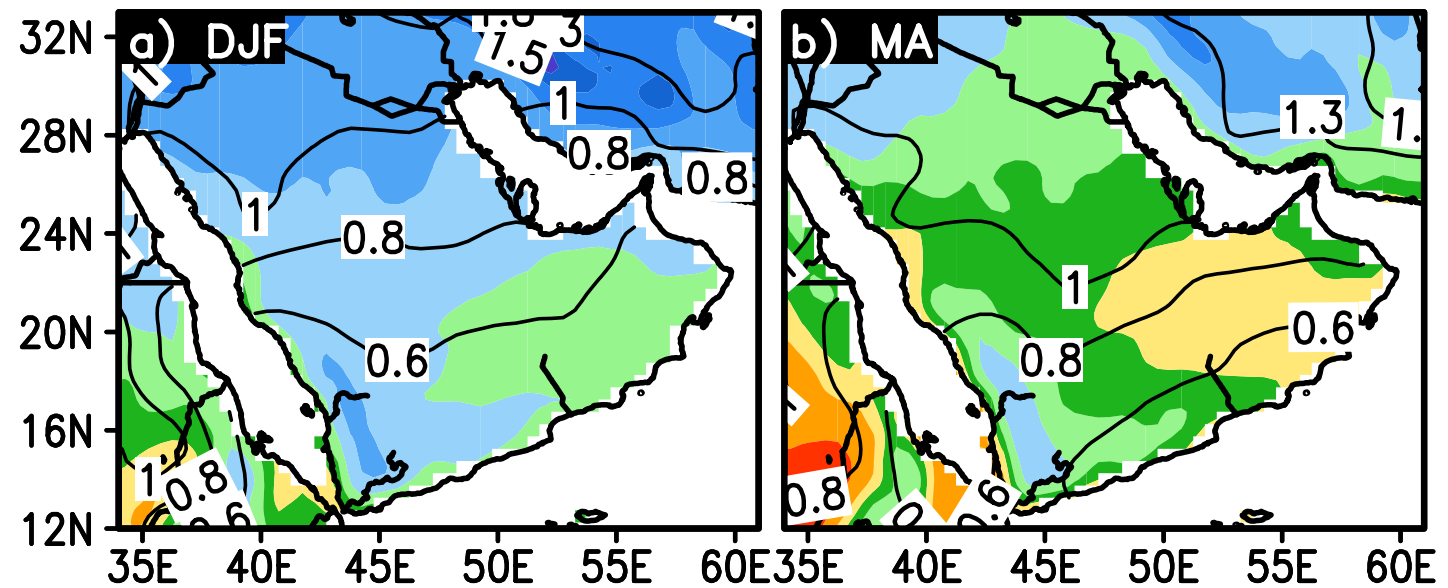

35

33

30
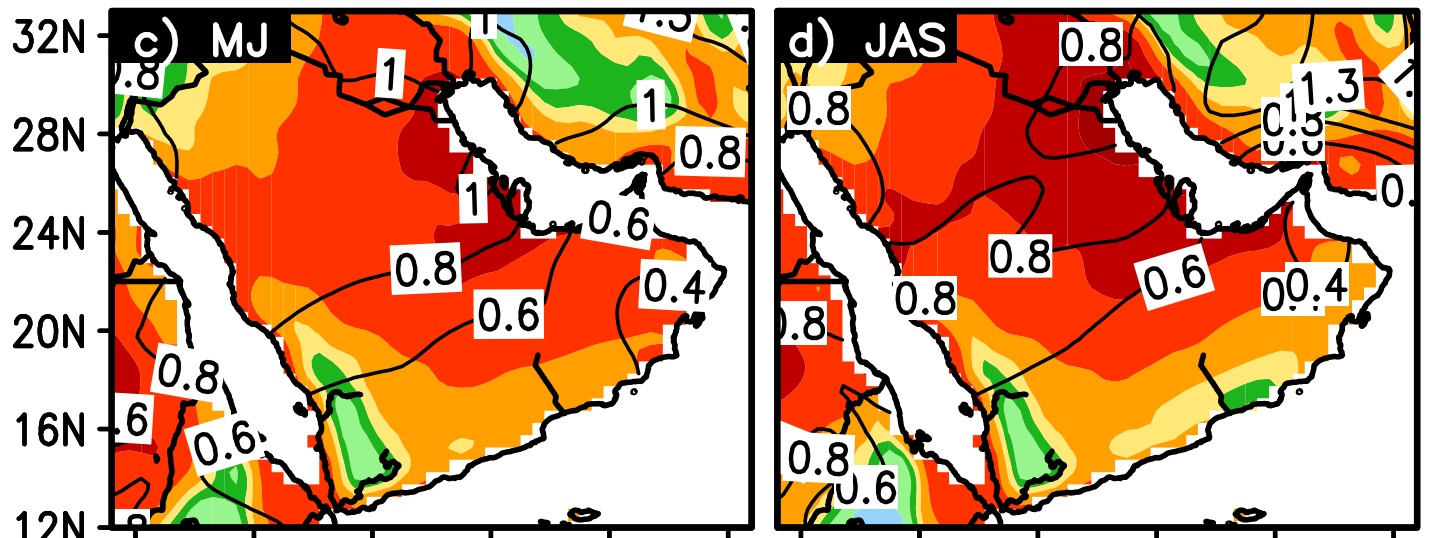

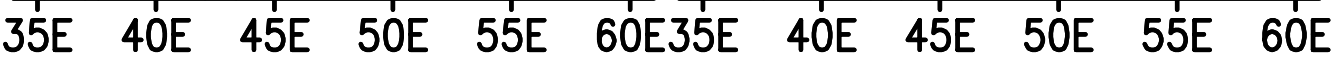

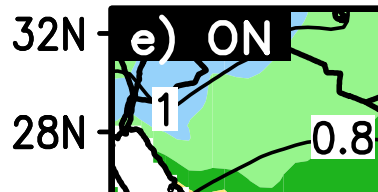

$24 \mathrm{~N}$

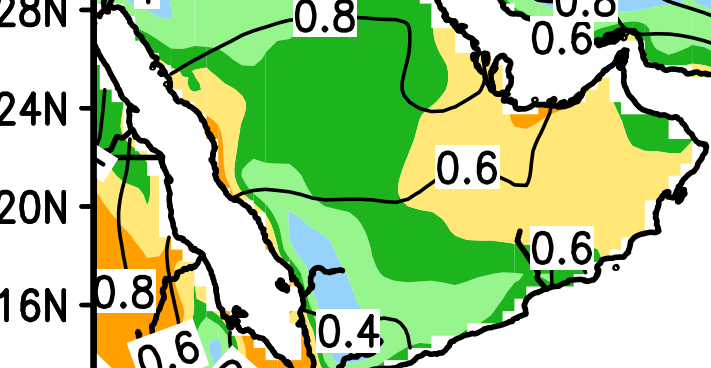

$16 \mathrm{~N}$ 0.8

$12 \mathrm{~N}$
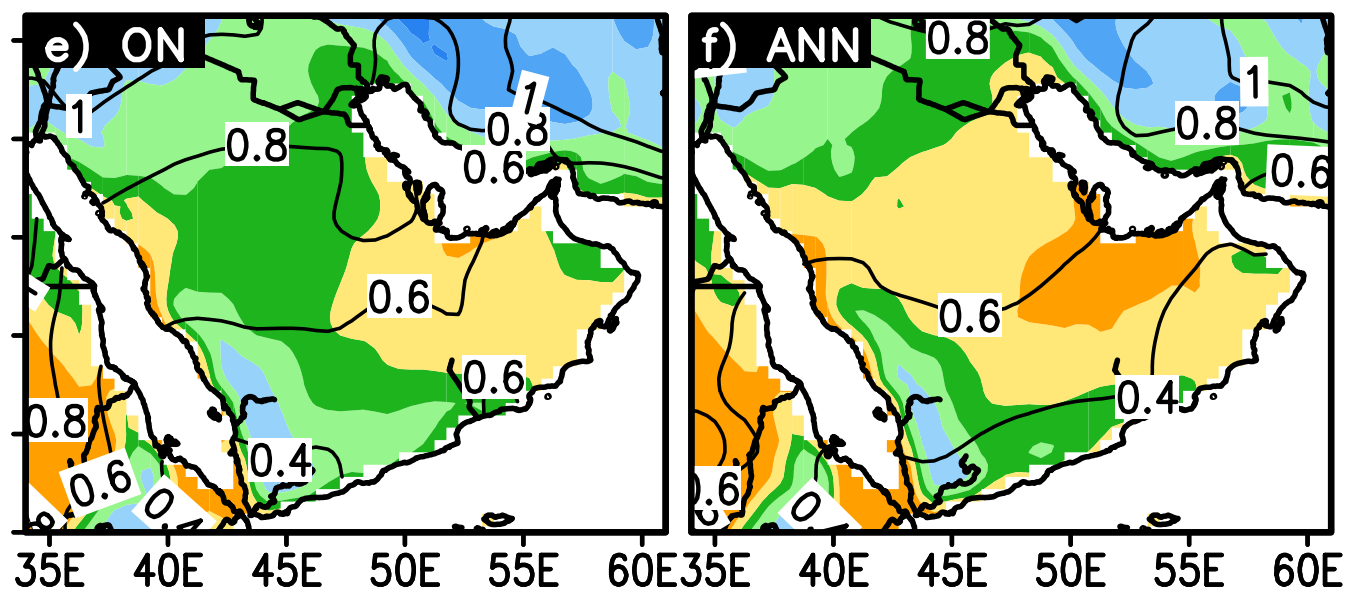


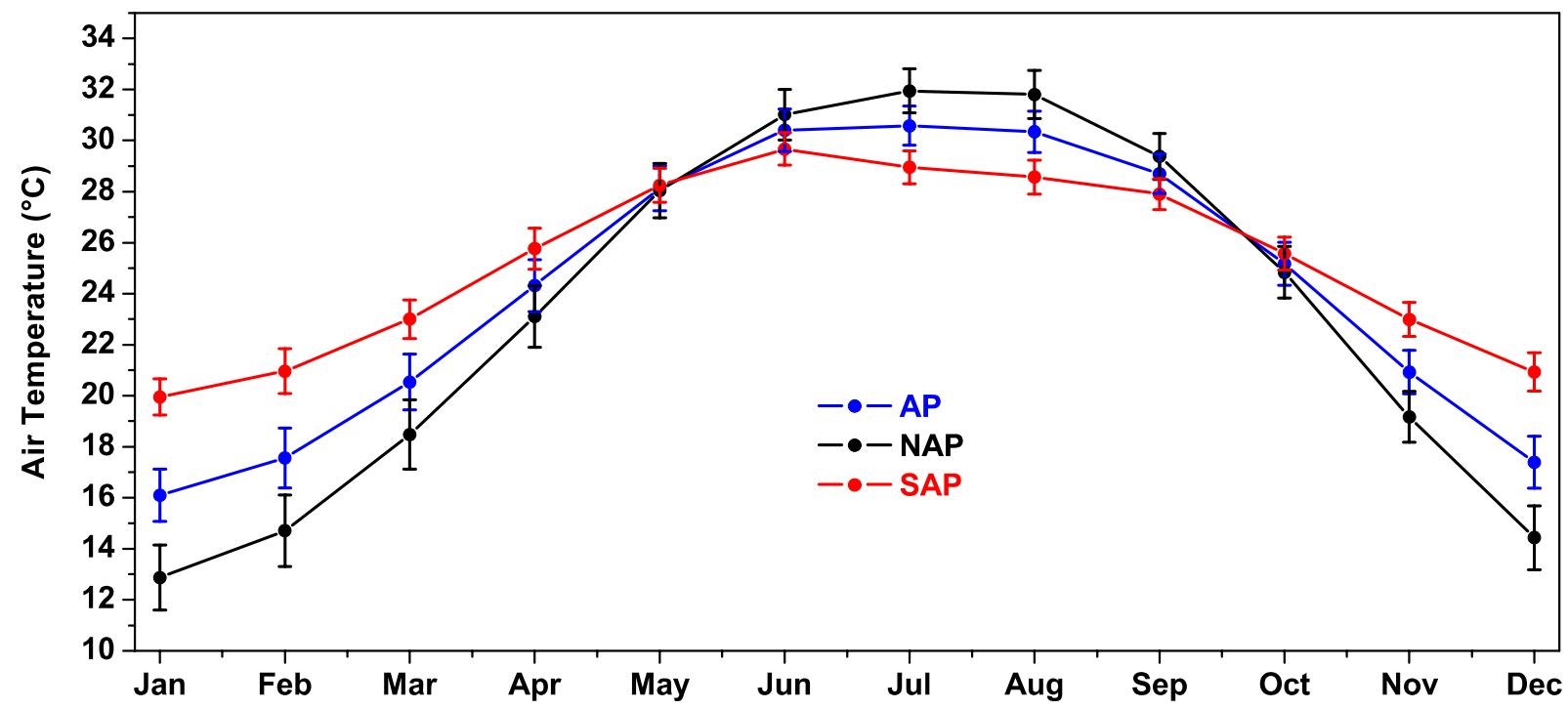

730

731 Figure 2. Annual cycle of surface air temperature $\left({ }^{\circ} \mathrm{C}\right)$ over the northern Arabian Peninsula $732\left(22-32^{\circ} \mathrm{N}, 35-60^{\circ} \mathrm{E}\right)$, the southern Arabian Peninsula $\left(12-22^{\circ} \mathrm{N}, 35-60^{\circ} \mathrm{E}\right)$ and the whole 733 Arabian Peninsula $\left(12-32^{\circ} \mathrm{N}, 35-60^{\circ} \mathrm{E}\right)$ for the period 1960-2010. Vertical bars indicate 734 standard deviation values.

735

736 

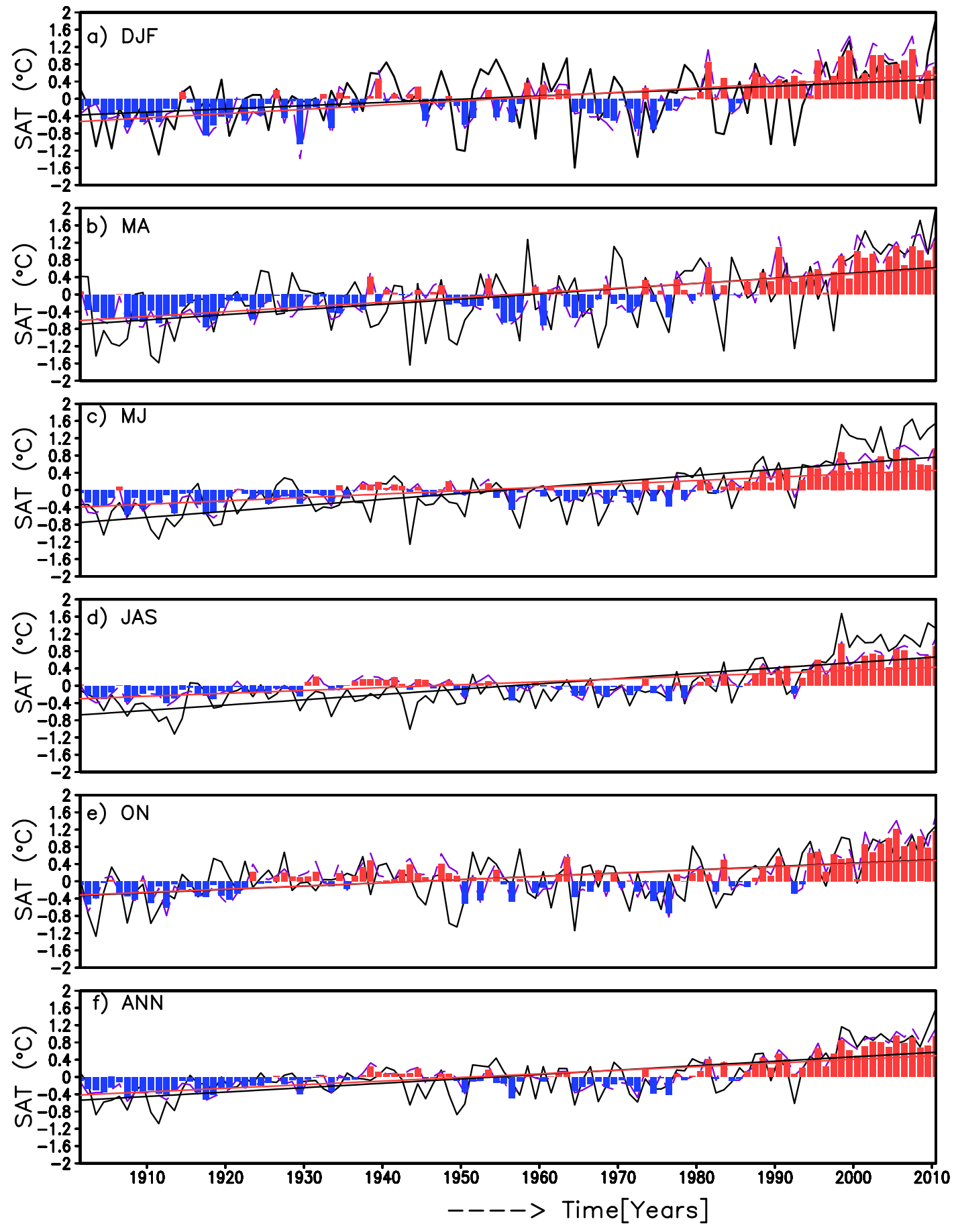

739 Figure 3. Time series of seasonal and annual mean air temperature anomalies (relative to the

740 mean of 1961-1990) over the globe (red), northern hemisphere (purple) and the Arabian

741 Peninsula (black) during the period 1901-2010. Positive (negative) anomalies are shown in red 742 (blue). 

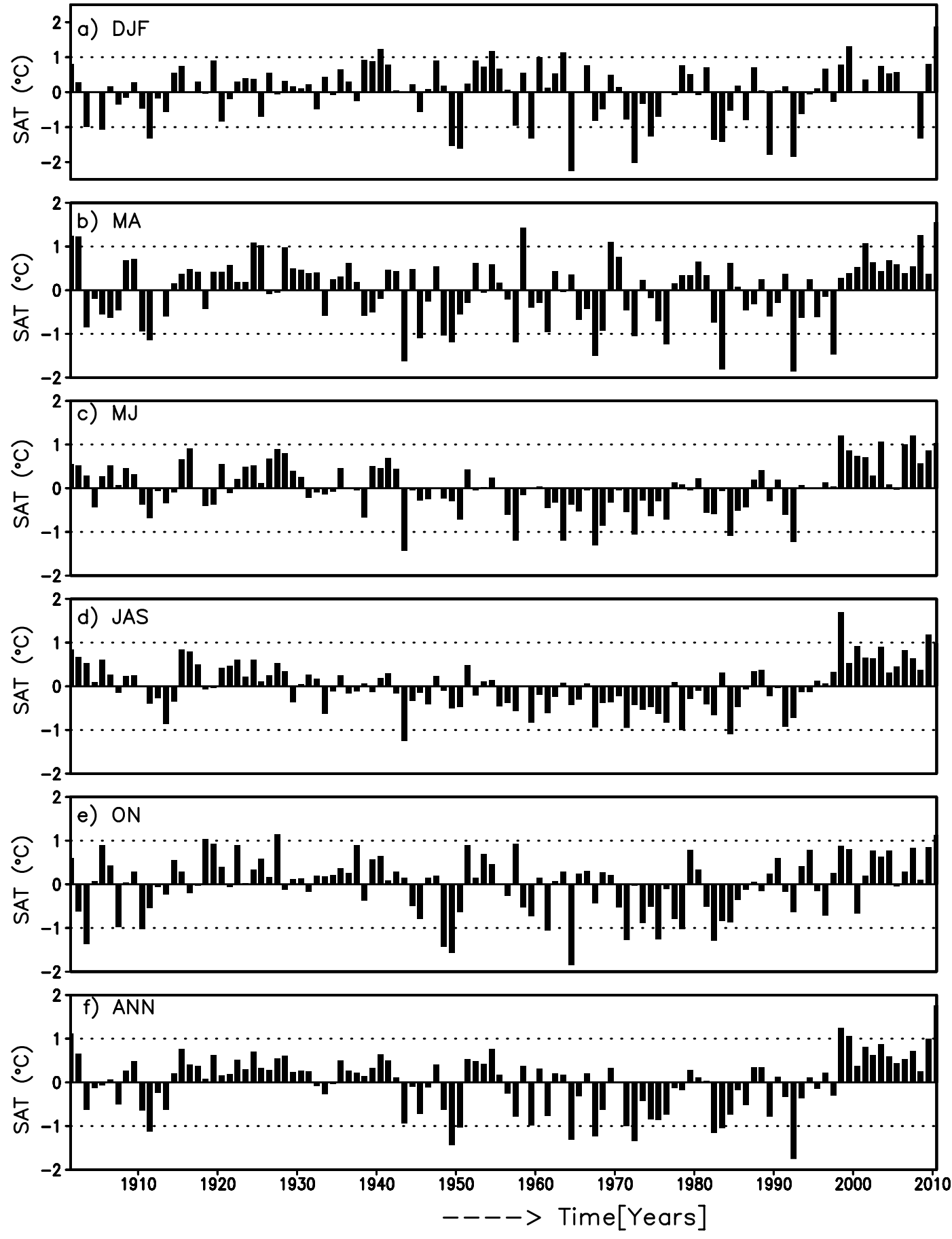

745 Figure 4. Seasonal variations of detrended air temperature anomalies $\left({ }^{\circ} \mathrm{C}\right)$ in the AP during the 746 period 1901-2010. 
Warm composites
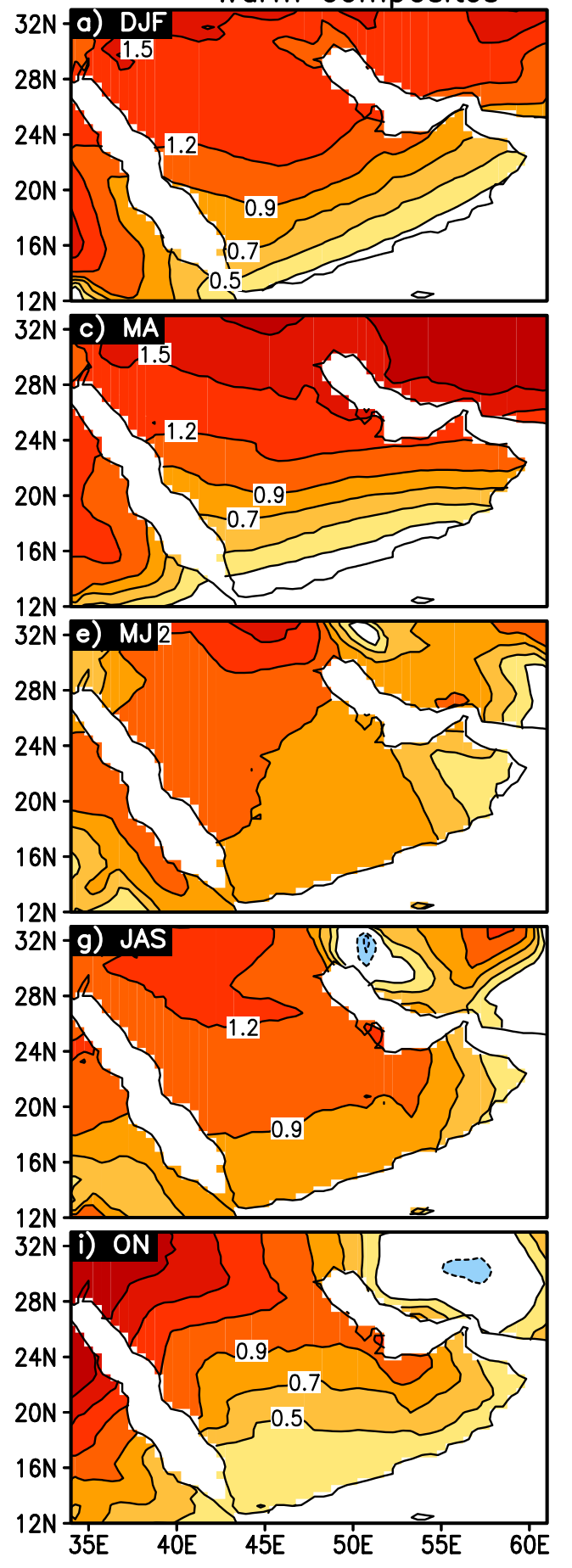

Cold composites
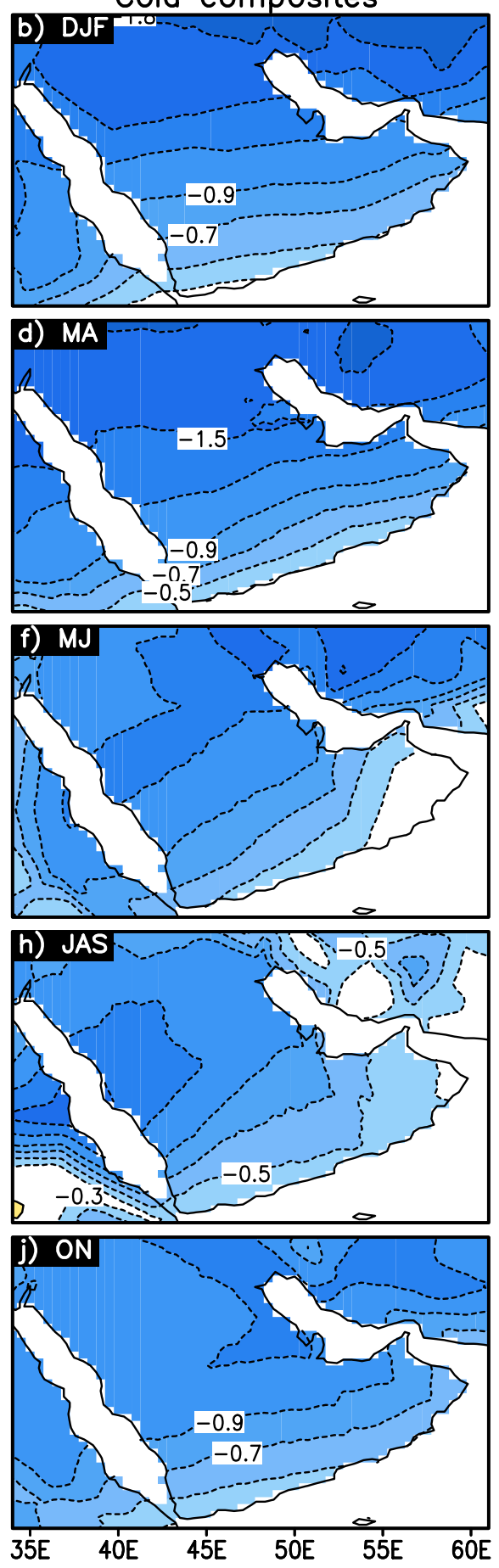

749 Figure 5. Composite of air temperature anomalies $\left({ }^{\circ} \mathrm{C}\right)$ for warm years (left) and cold years 750 (right) during DJF, MA, MJ, JAS and ON. 

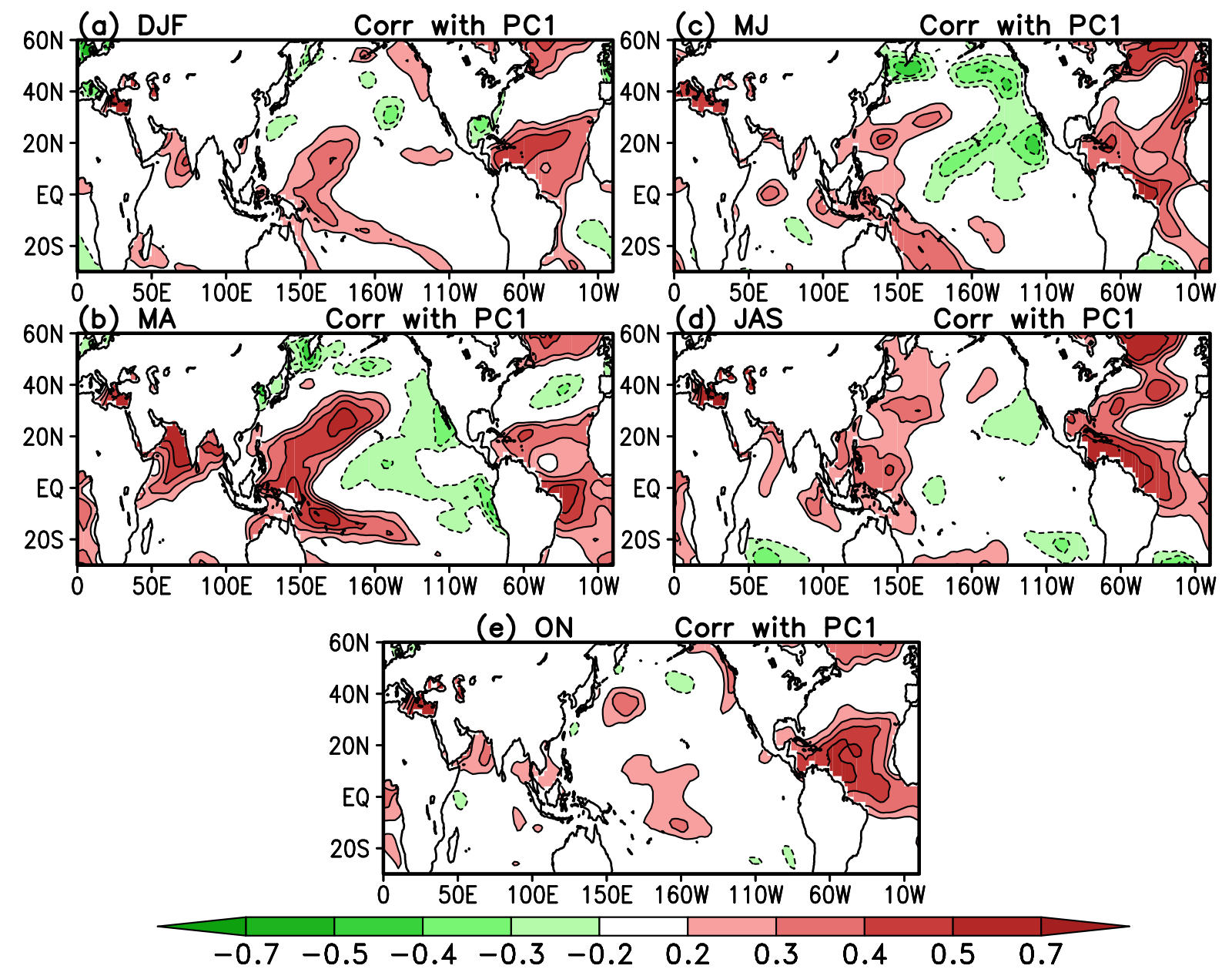

754 Figure 6. Spatial maps of correlations between the PC1 of the AP surface temperature and the 755 global sea surface temperature for the period of 1960-2010. Area of 95\% significant level is 756 shaded; area of $99 \%$ significant level is contoured. 

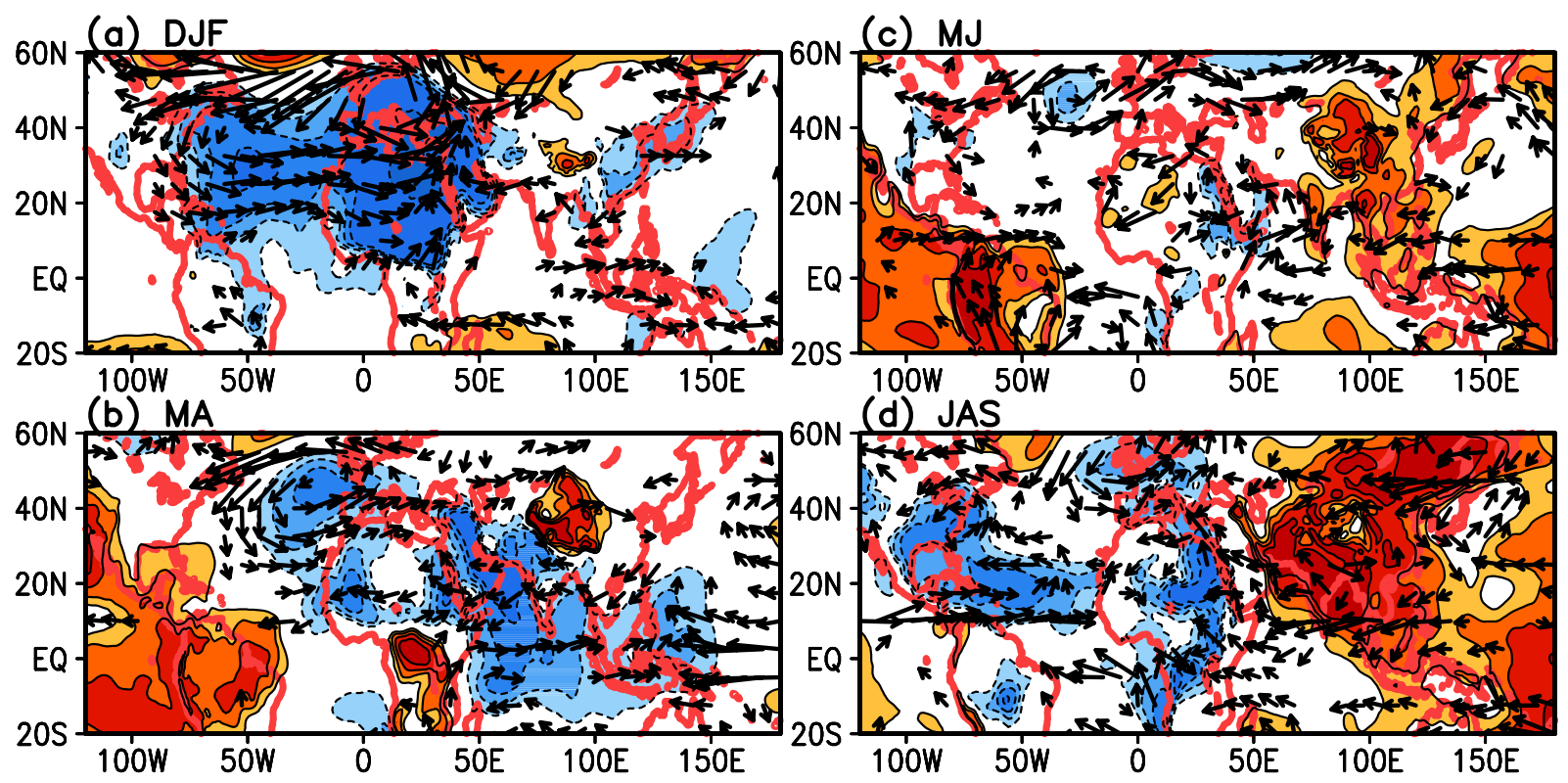

$\overrightarrow{5.0}$

(e) ON

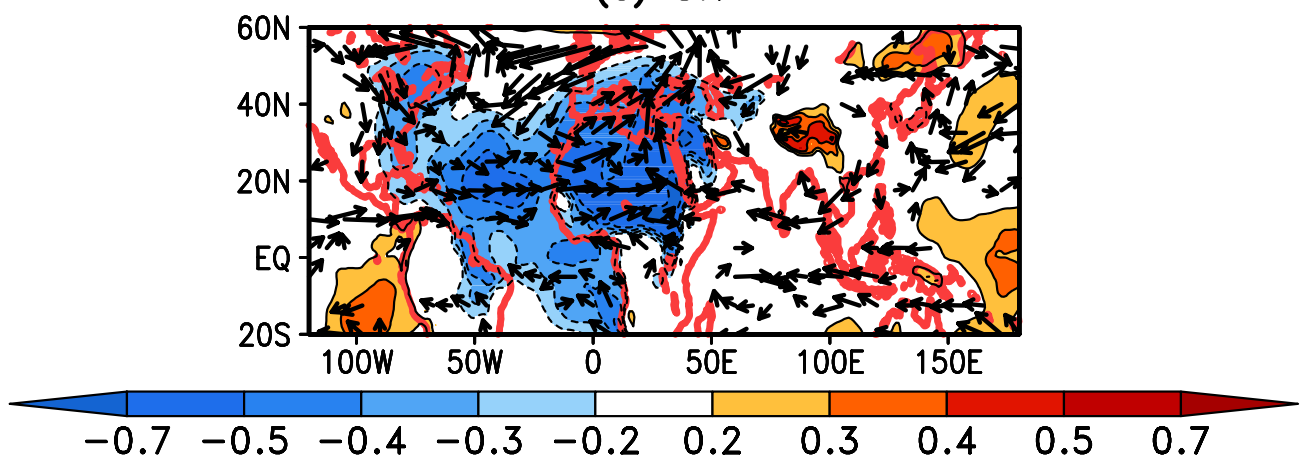

762 Figure 7. Spatial maps of correlations between the AP SAT and MSLP (hPa; shaded);

763 regression of low-level $(850 \mathrm{hPa})$ winds $\left(\mathrm{ms}^{-1}\right.$; vectors) with the AP SAT for the period 19607642010.

765

766 


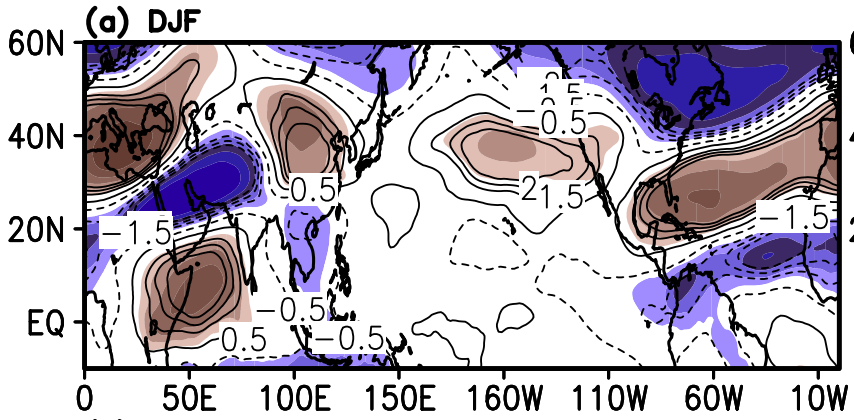

(c) $M J$
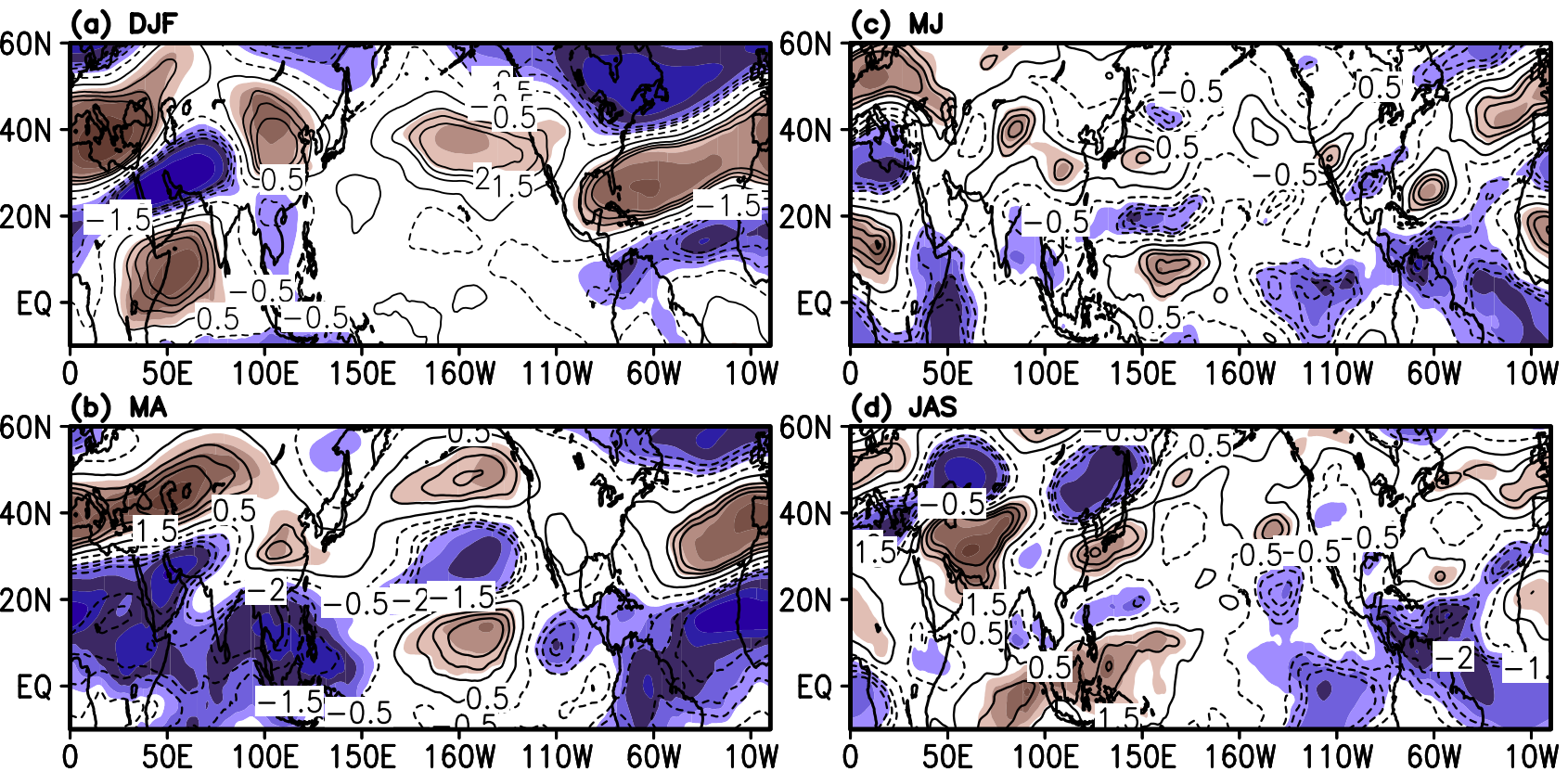

(e) ON

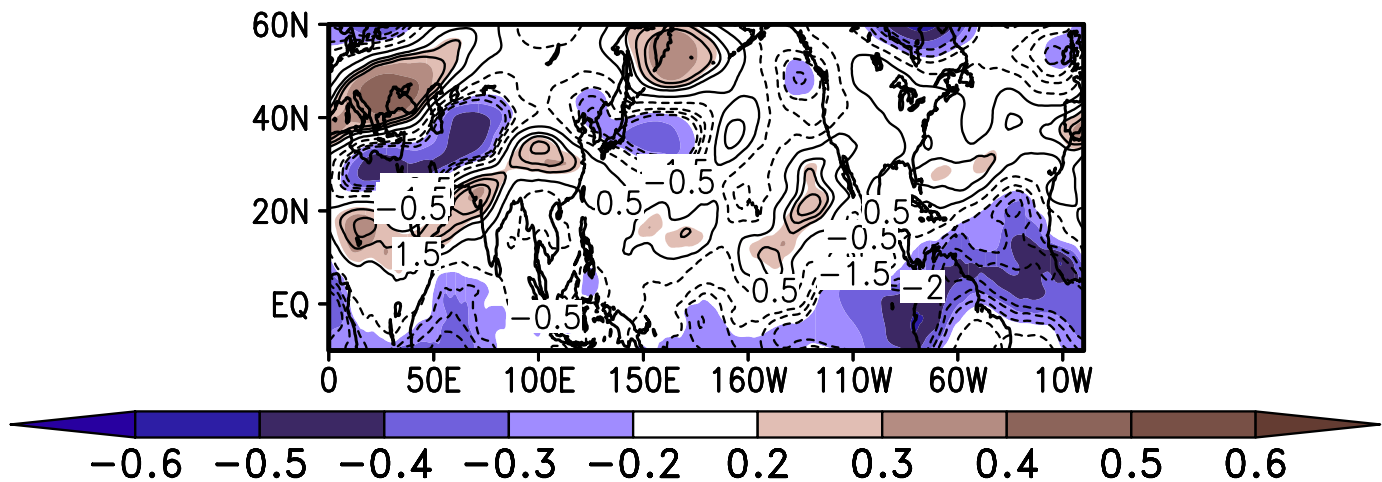

769

770 Figure 8. Same as Figure 7 but for upper-level $(200 \mathrm{hPa})$ winds $\left(\mathrm{ms}^{-1}\right)$. Correlation is shaded

771 and regression is contoured.

772

773

774 
(a) DJF

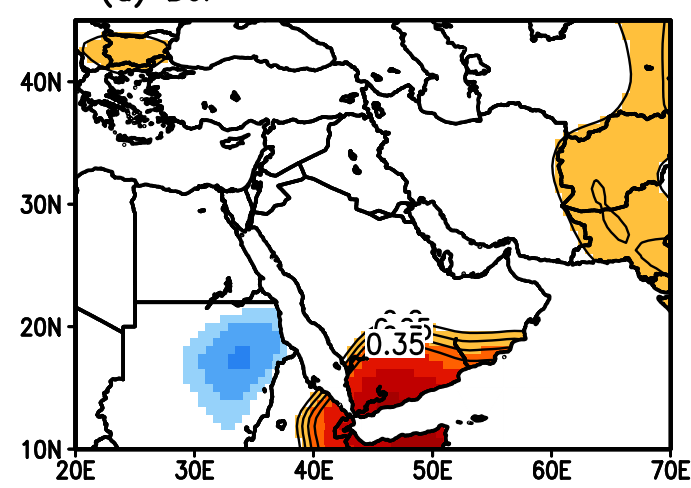

(c) $\mathrm{MJ}$

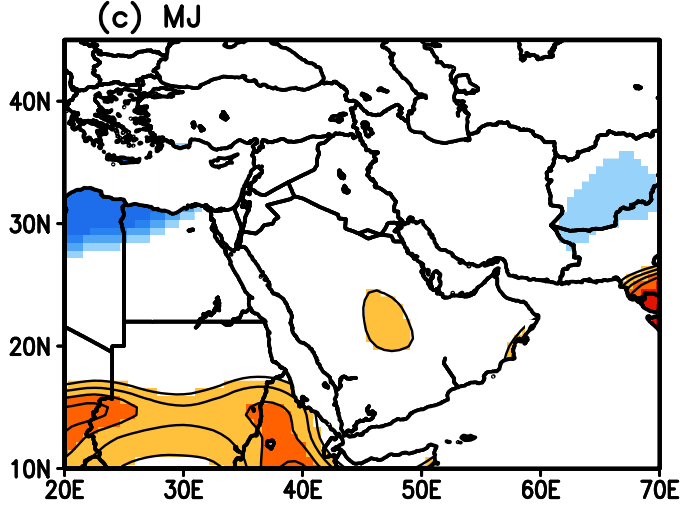

(e) ON

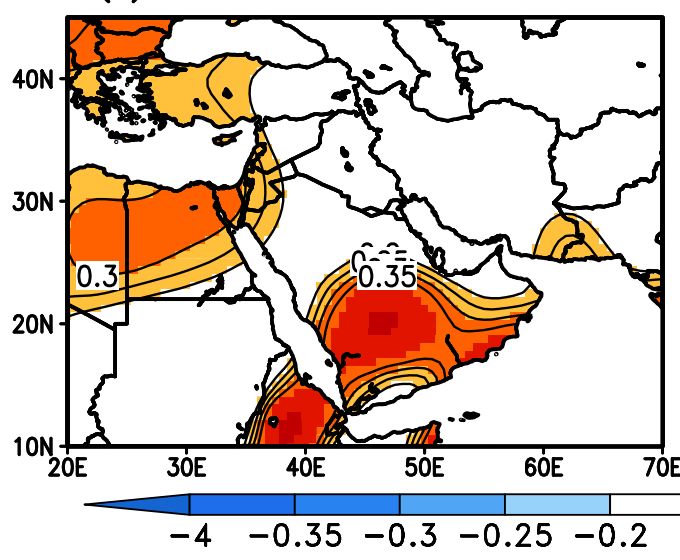

(b) MA

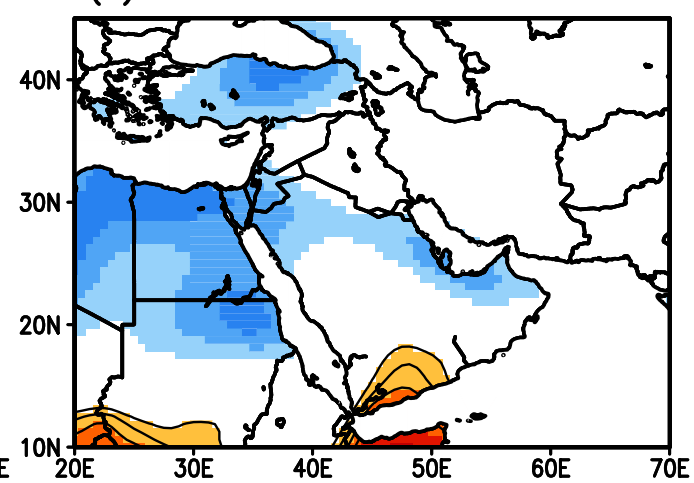

(d) JAS

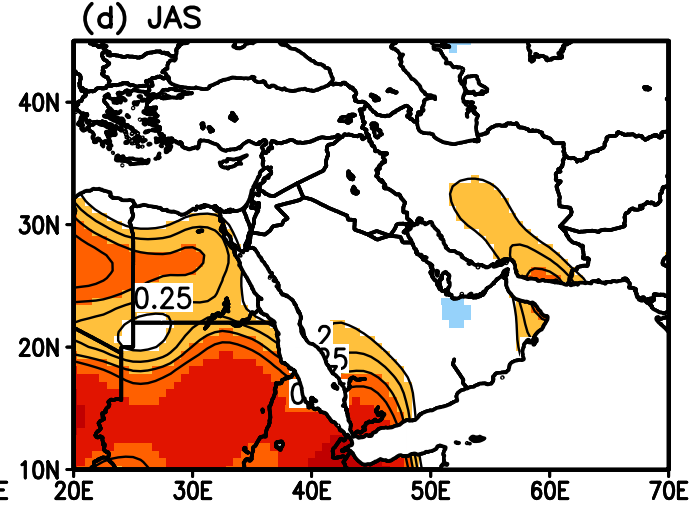

(f) ANNUAL

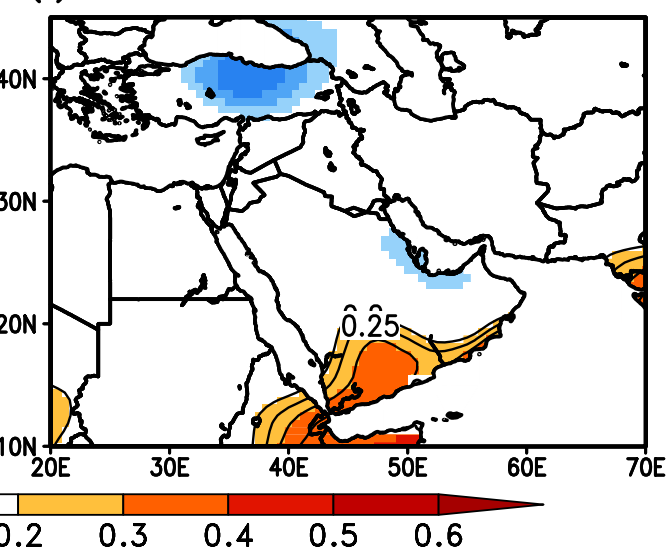

776 Figure 9. Horizontal distribution of the correlation coefficient between the ENSO index and

777 the AP SAT. 
(a) DJF

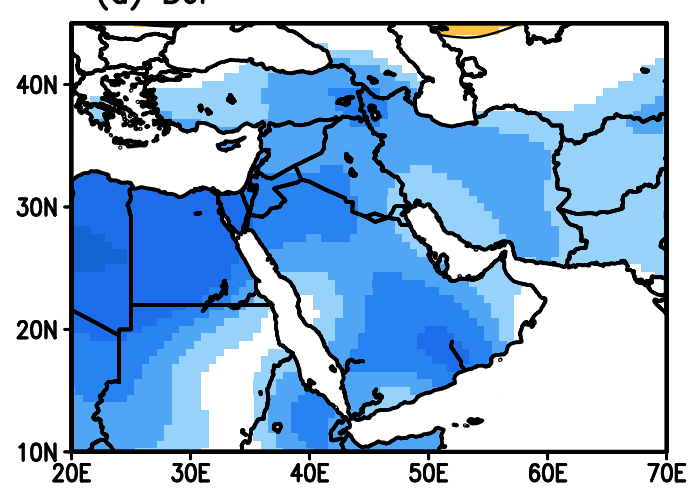

(c) $\mathrm{MJ}$

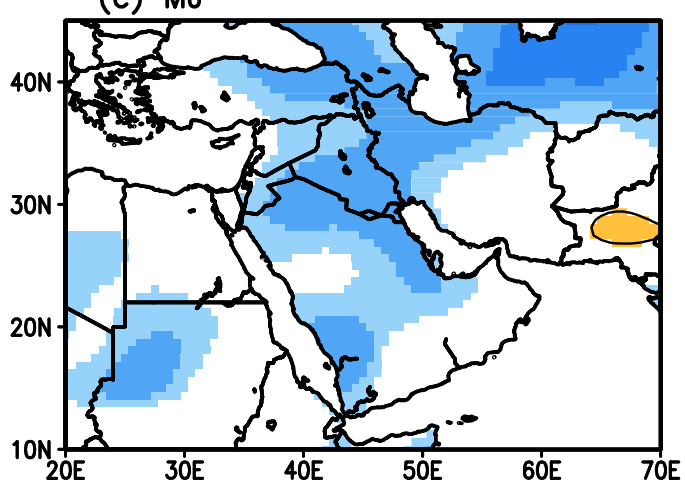

(e) $\mathrm{ON}$

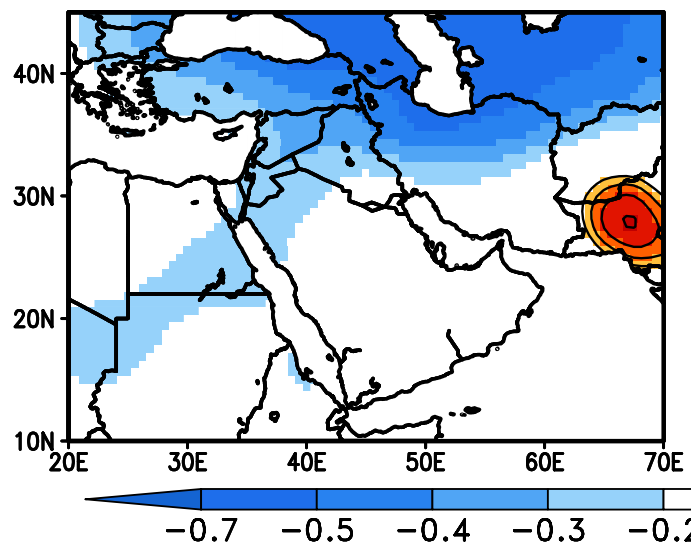

(b) MA

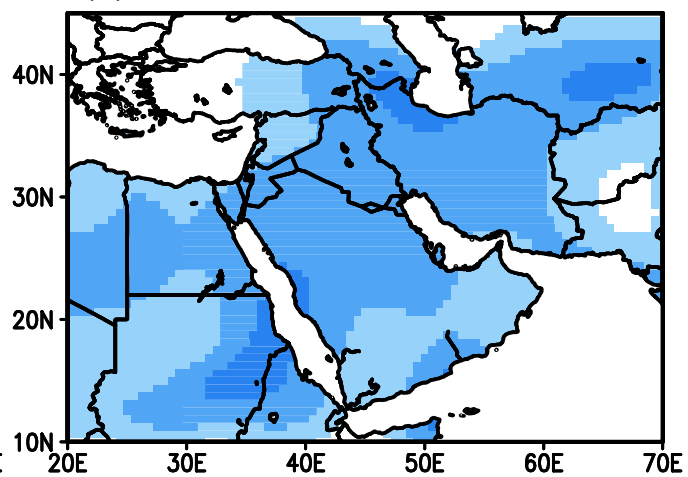

(d) JAS

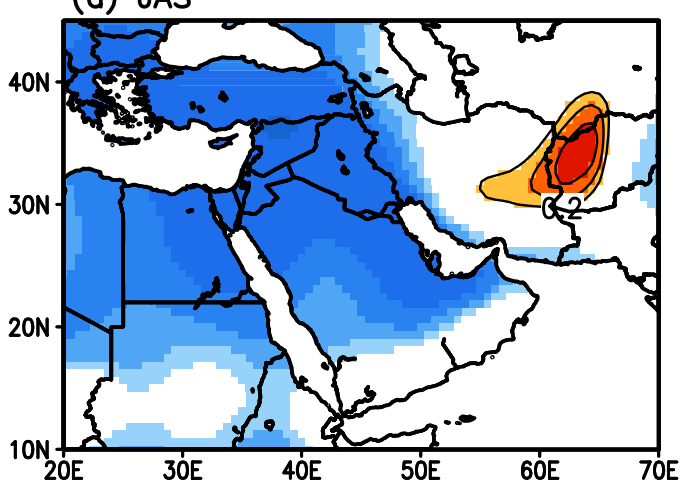

(f) ANNUAL

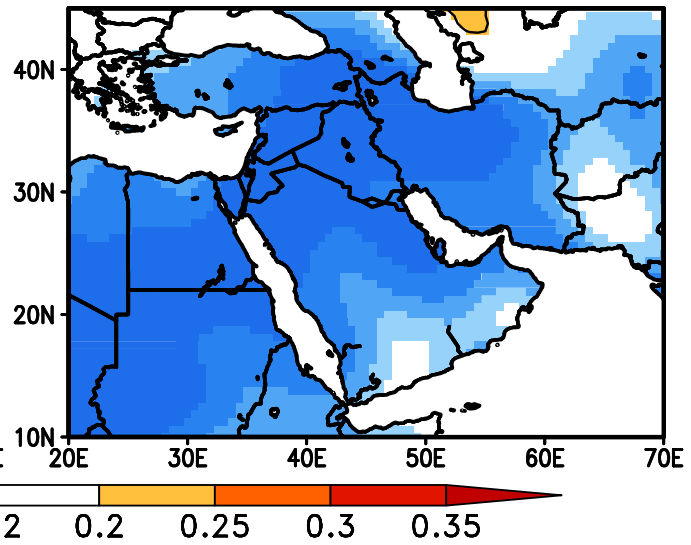

782

783

784

Figure 10. Same as Figure 9 but for NAO index.

785 

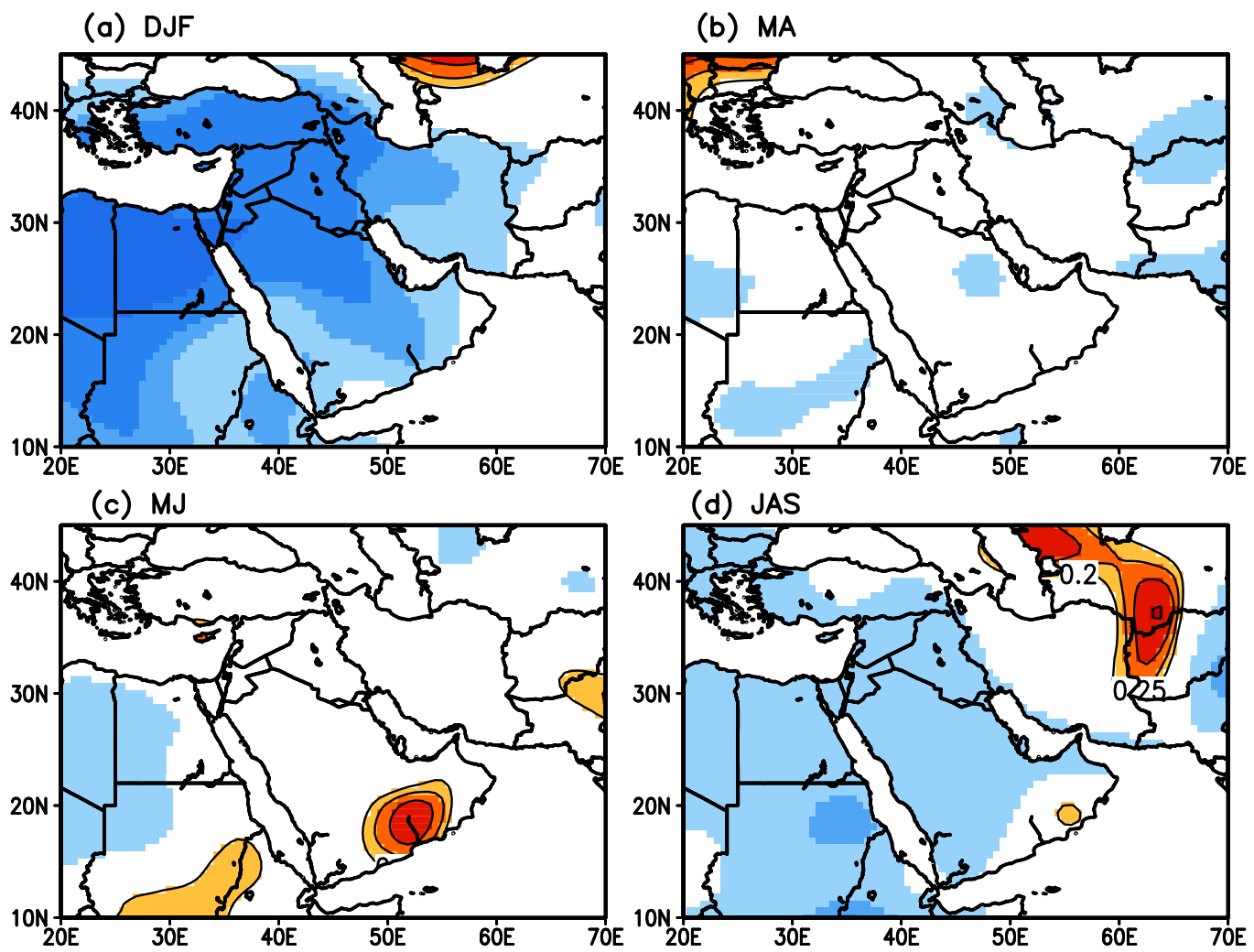

(e) $\mathrm{ON}$

(f) ANNUAL

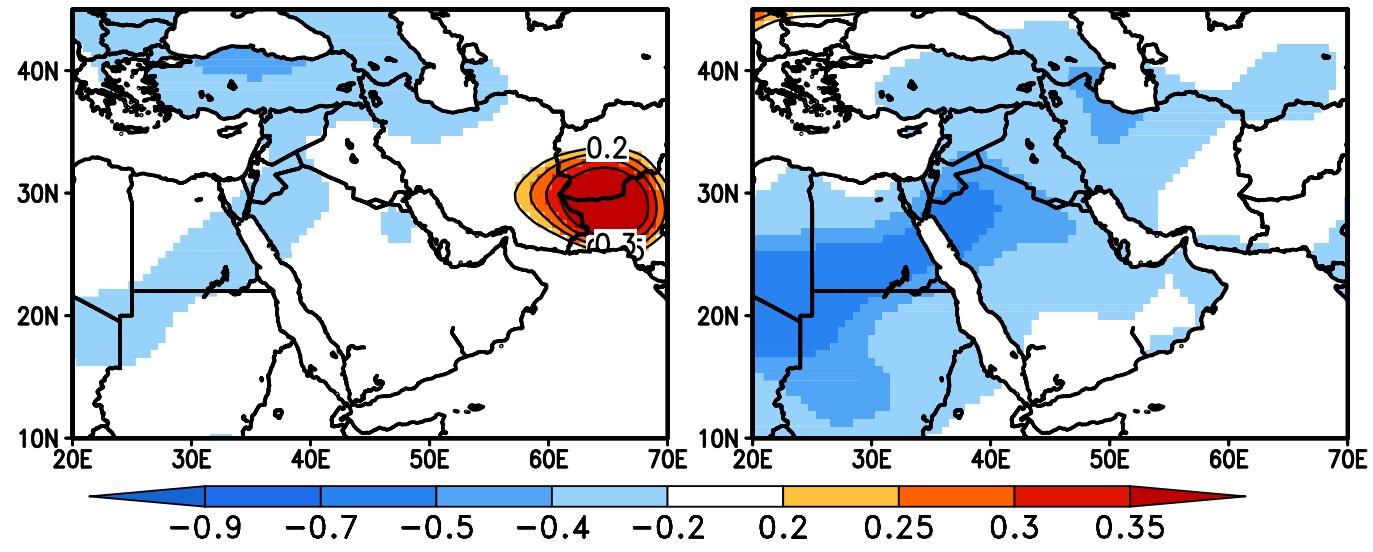

Figure 11. Same as Figure 9 but for AO index. 


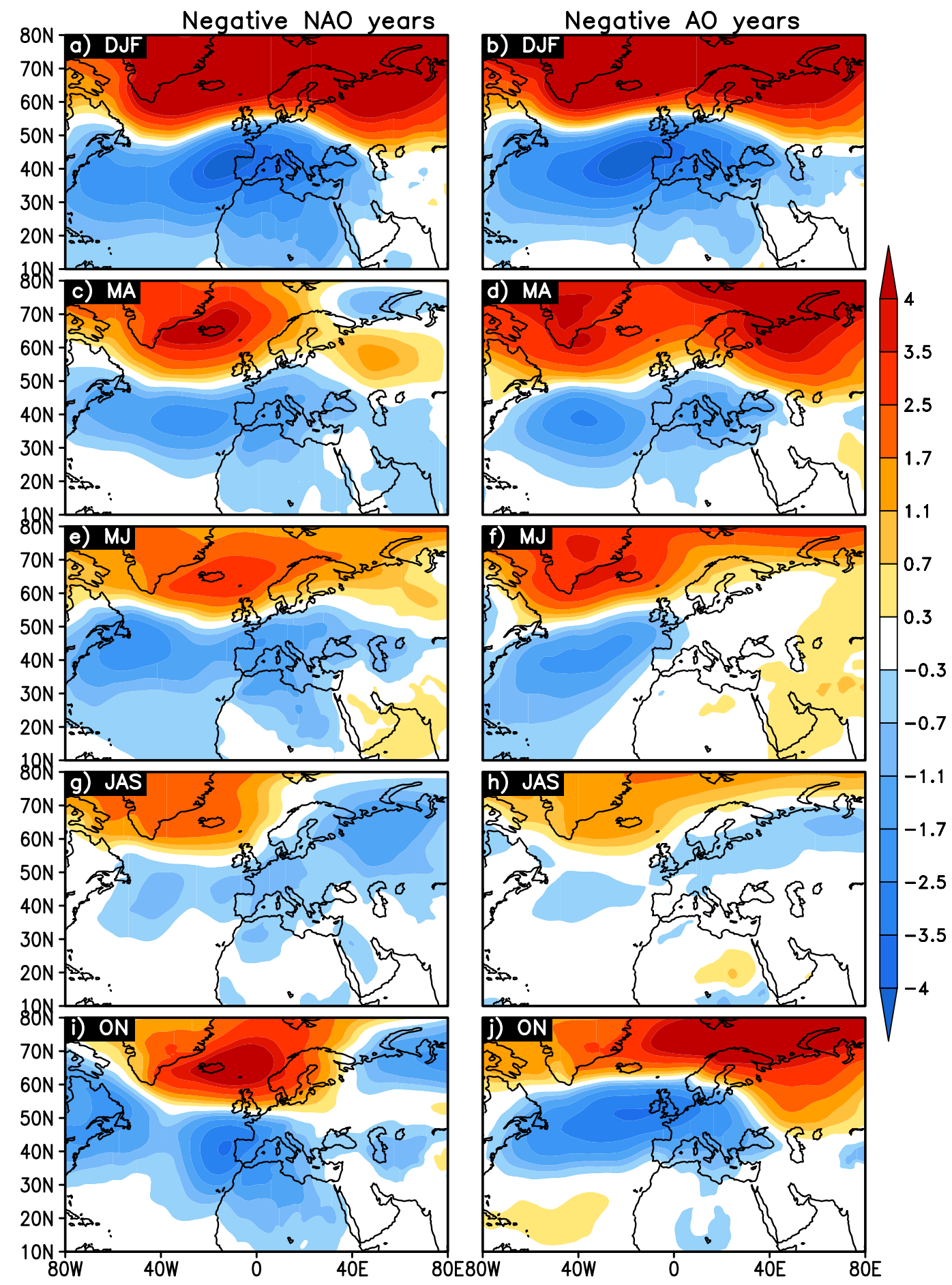

793 Figure 12. Spatial patterns of sea level pressure anomalies during negative modes of NAO (left 794 panel) and AO (right panel) for different seasons. 
798 Table 1: Seasonal and annual SAT trends $\left({ }^{\circ} \mathrm{C} /\right.$ decade), correlation coefficients (statistically 799 significant) between the AP temperature and the global temperature for the period 1901-2010.

800

801

802

803

804

805

806

807

808

\begin{tabular}{|l|l|l|l|}
\hline Season & \multicolumn{1}{|c|}{ AP } & Global & CC \\
\hline DJF & 0.07 & 0.09 & 0.5 \\
\hline MA & 0.12 & 0.10 & 0.54 \\
\hline MJ & 0.13 & 0.07 & 0.8 \\
\hline JAS & 0.12 & 0.06 & 0.85 \\
\hline ON & 0.07 & 0.07 & 0.6 \\
\hline ANN & 0.10 & 0.08 & 0.7 \\
\hline
\end{tabular}

809

810 Table 1: Seasonal and annual SAT trends $\left({ }^{\circ} \mathrm{C} /\right.$ decade), correlation coefficients (statistically

811 significant) between the AP temperature and the global temperature for the period 1901-2010.

812

813 